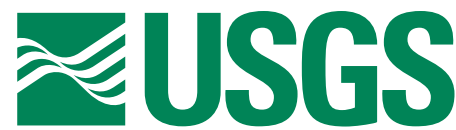

science for a changing world

In cooperation with the Washington Department of Transportation, Burlington Northern Santa Fe Railway, and Shannon and Wilson, Inc.

\title{
Hydrologic Monitoring of Landslide-Prone Coastal Bluffs near Edmonds and Everett, Washington, 2001-2004
}

By Rex L. Baum, Jonathan P. McKenna, Jonathan W. Godt, Edwin L. Harp, and

Steven R. McMullen (Shannon and Wilson, Inc.)

Open-File Reports are used for the dissemination of information that must be released immediately to fill a public need or for information that is not sufficiently refined to warrant formal publication. As such, Open-File Reports should not be viewed as final reports of major scientific investigations. Because of their preliminary nature and possibility of being superseded, Open-File Reports do not introduce new or revised geologic, stratigraphic, hydrologic, or taxonomic nomenclature. In particular, Article 4(a) of the North American Stratigraphic Code excludes open-file releases for the naming or revising of formal geologic units.

Any use of trade, firm, or product names is for descriptive purposes only and does not imply endorsement by the U.S. Government.

\section{U.S. Geological Survey Open-File Report 2005-1063}

\author{
U.S. Department of the Interior \\ U.S. Geological Survey
}




\section{Introduction}

Landslides on coastal bluffs between Seattle and Everett, Washington, have posed a major safety hazard to transportation since the 1800s. Large numbers of landslides in 1996 and 1997 resulted in damage to property and temporary disruption of railroad service; the January 15, 1997, Woodway landslide derailed several cars of a freight train (W.A. Hultman and D.N. McCulloch, Shannon and Wilson, Inc., written commun., 1997; Baum and others, 1998). With the exception of the Woodway landslide, the vast majority of these landslides were shallow. 50-m-high bluff; beneath the till is a layer of glacial advance outwash that overlies dense glaciolacustrine silt (Minard, 1983). The railroad embankment conceals the toe of the bluff, including the basal contact of the outwash. The soil-water instruments for this study are installed in dense glacial outwash sand 25-35 m above sea level (fig. 1B and 1C). The outwash consists of dense, uniform, medium sand. Mechanical weathering of the outwash produces a loose sandy colluvium mantle that covers much of the lower bluff. The colluvium is thickest near the toe of the bluff.

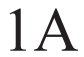

In 2001, a cooperative monitoring effort between the U.S. Geological Survey (USGS), the Burlington Northern Santa Fe Railway (BNSF), BNSF's geotechnical consultant, Shannon and Wilson, Inc., and the Washington Department of Transportation was begun to determine whether near-real-time monitoring of rainfall and shallow subsurface hydrologic conditions could be used to anticipate landslide activity on the bluffs. Monitoring currently occurs at two sites - one near Edmonds, Washington, and the other near Everett, Washington (fig. 1A). During initial planning, the USGS proposed to evaluate the monitoring results at the end of 3 years. This report summarizes site conditions, methods, system reliability, data, and scientific results, and identifies possible future directions for development of monitoring and early warning of impending landslide activity.

\section{Site Conditions}

The coastal bluffs at the Edmonds and Everett monitoring sites are underlain by subhorizontally bedded glacial and interglacial sediments, which include glacial advance outwash sand overlying glaciolacustrine silt deposits. Shallow landslides commonly occur in weathered glacial deposits and slope deposits (colluvium) on the bluffs after periods of relatively heavy rainfall or snowmelt. Lack of significant runoff from natural (unpaved) slopes during rainfall indicates that water enters the slopes by direct infiltration. Within the bluffs, water also flows laterally through sandy layers that rest on less permeable layers of silt or clay as indicated by the presence of seeps and springs.

\section{Edmonds Site}

The Edmonds site is on a west-facing bluff about 3 kilometers (km) north of downtown Edmonds, (BNSF milepost 19.6) where several shallow landslides occurred in 1996-1997 (Baum and others, 2000). A 3-meter (m)-thick layer of glacial till caps the
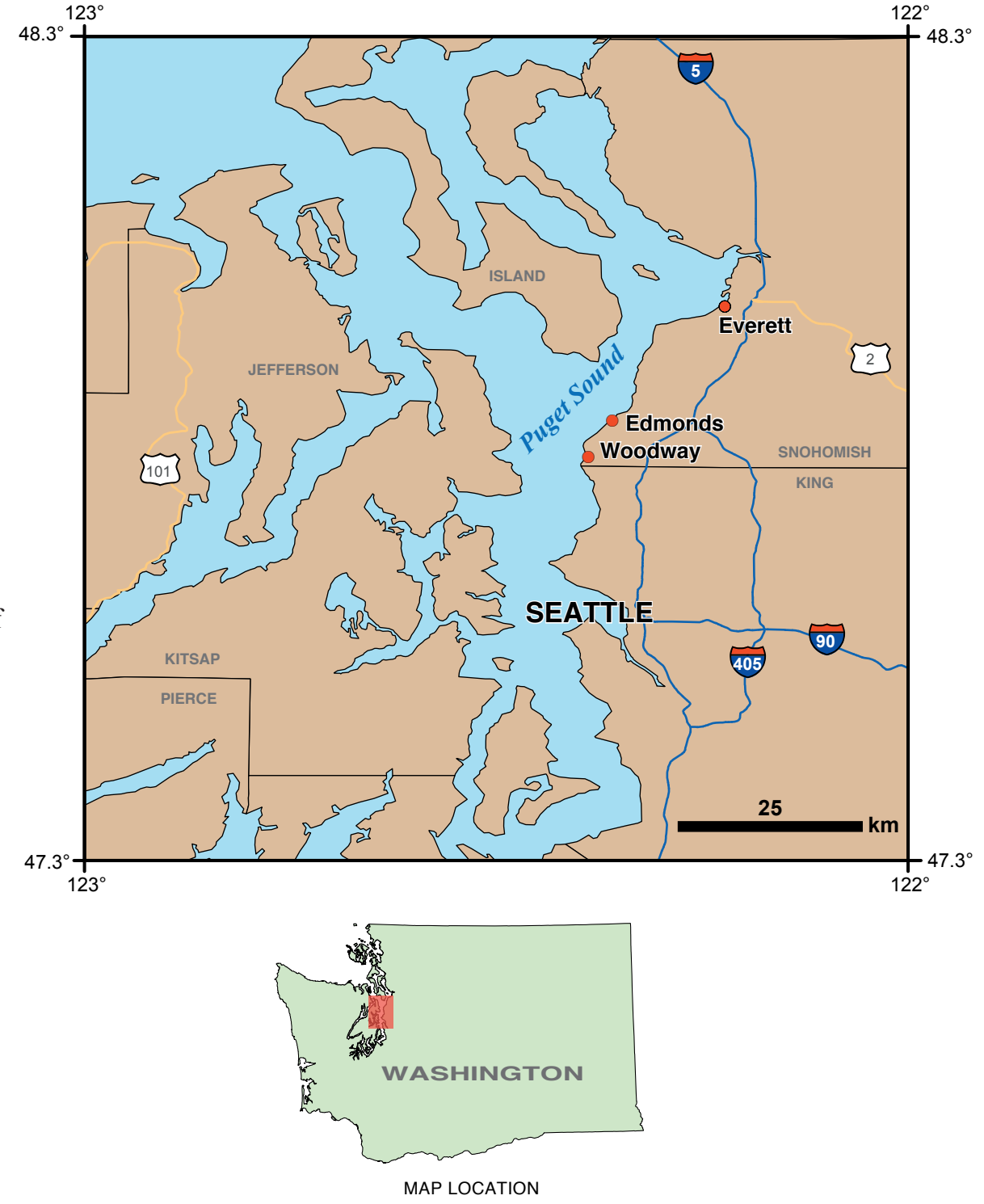

Figure 1. Map showing location of coastal bluff monitoring sites, Edmonds and Everett, Washington, and at the Woodway landslide, A. Solid circles show locations of monitoring sites along the shores of Puget Sound. B. Map showing instrument locations at the Edmonds site. C. Cross section showing instrument locations at the Edmonds site. D. Map showing instrument locations at the Everett site. E. Cross section showing instrument locations at the Everett site. 


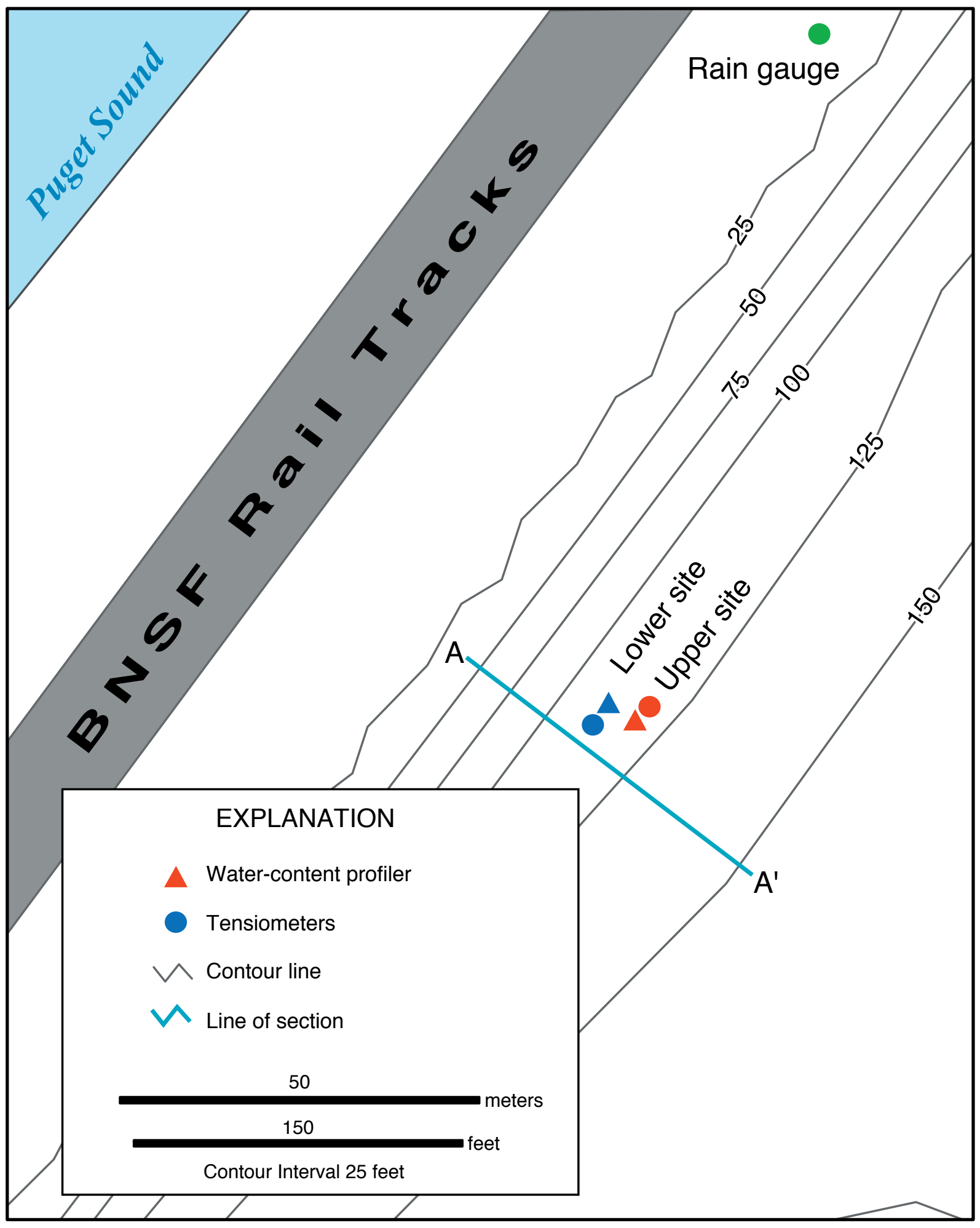




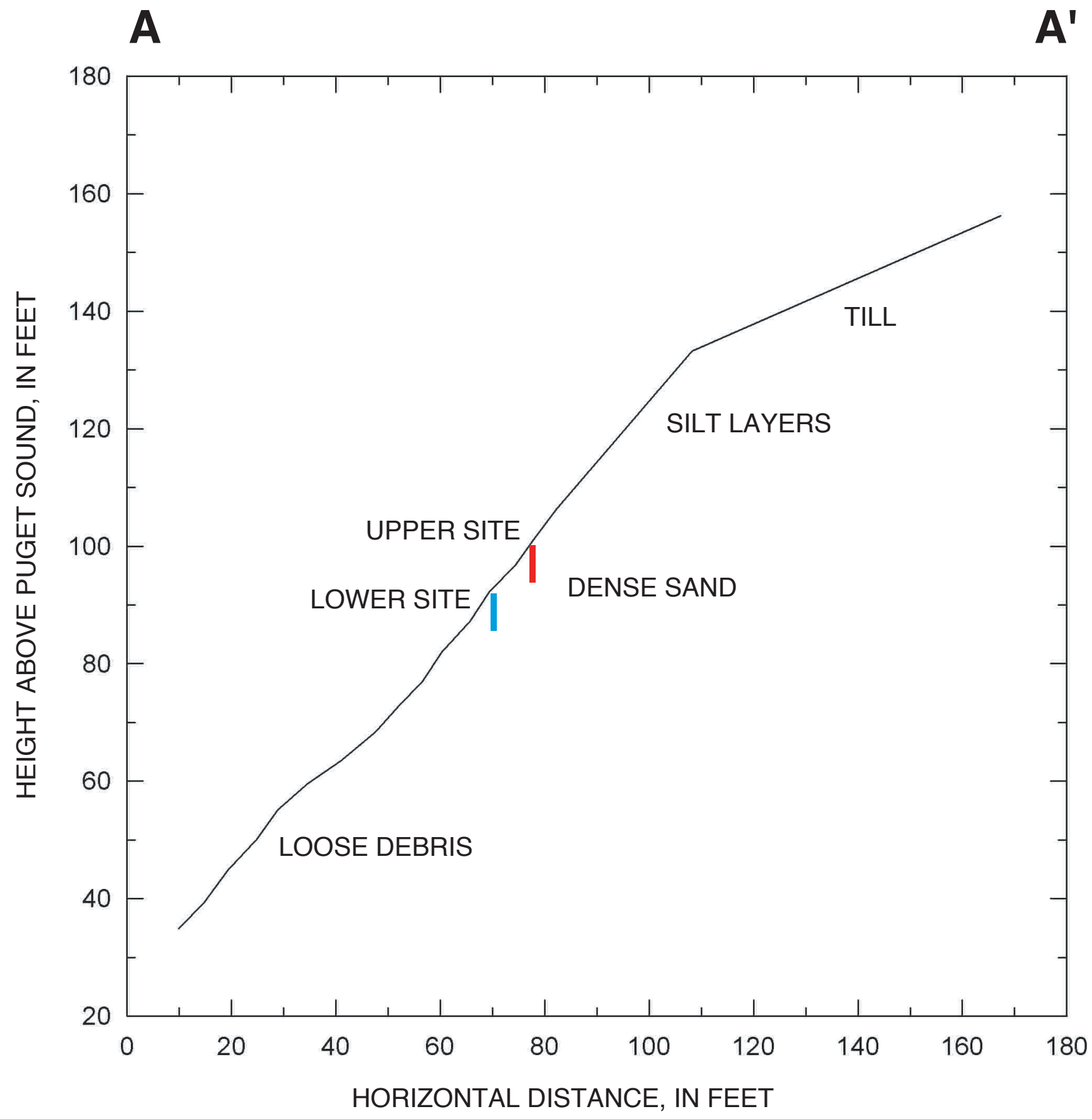




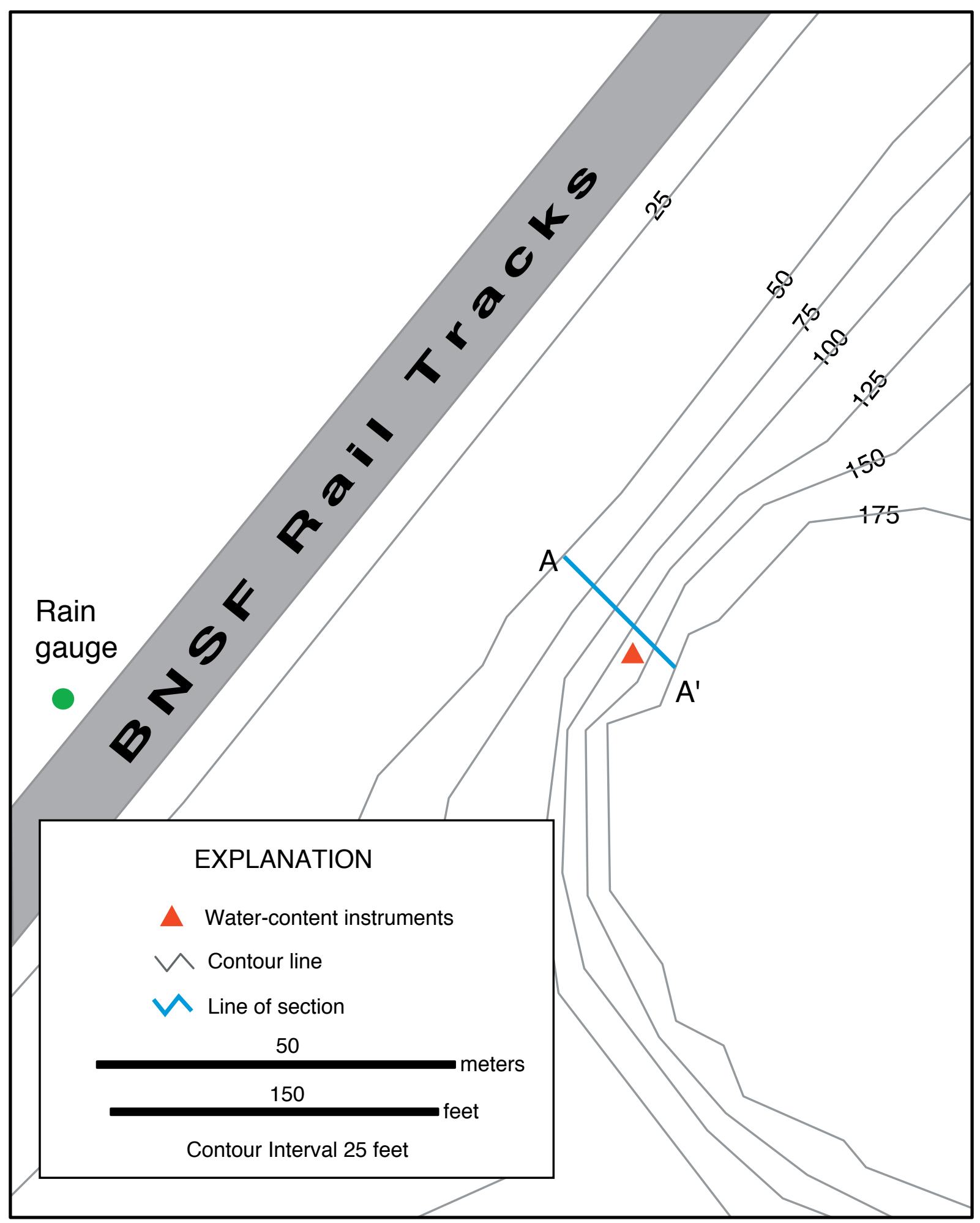




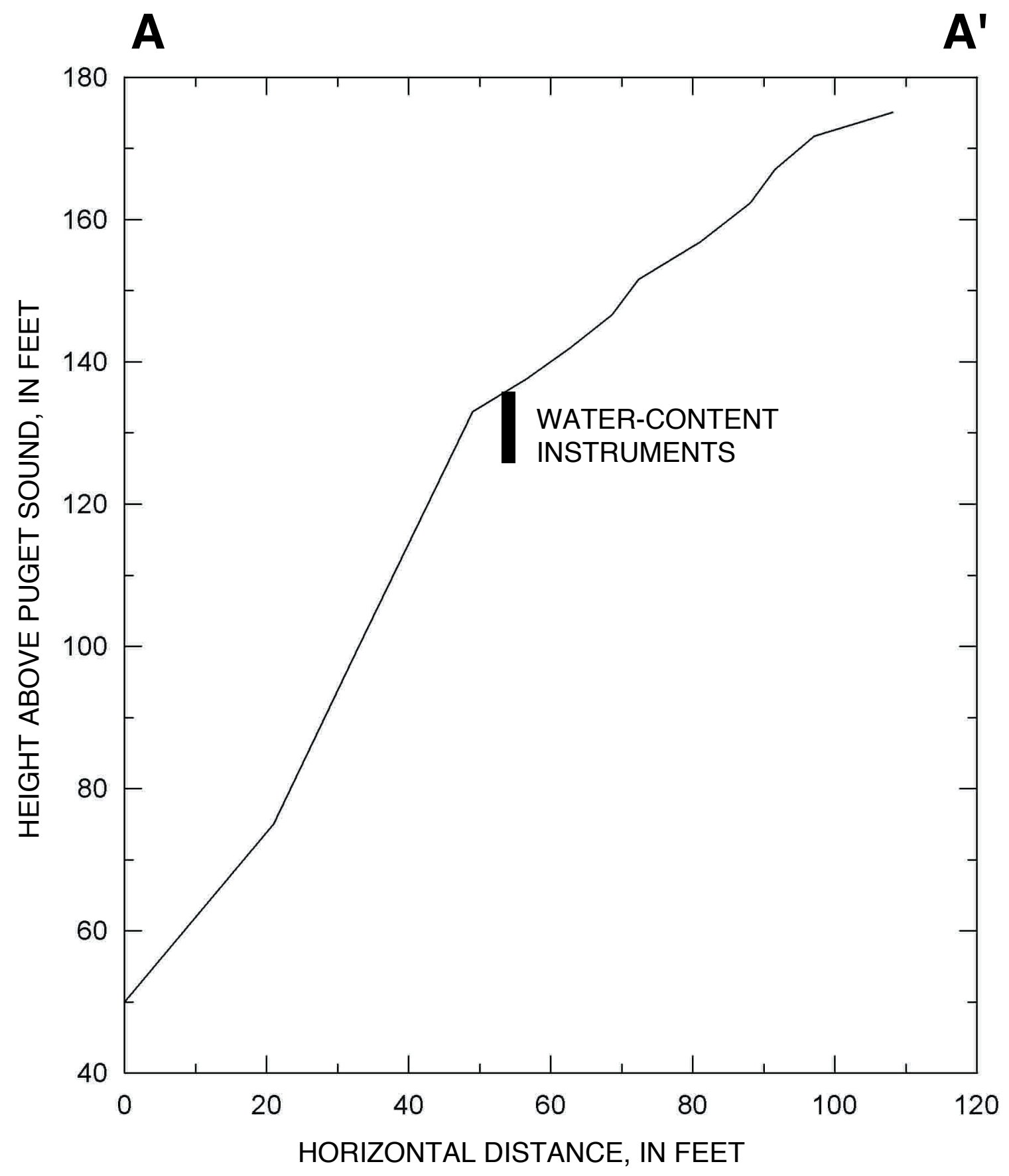




\section{Everett Site}

The Everett site is on a north-facing bluff adjacent to the BNSF tracks, near milepost 1784.4 (fig. 1D and 1E). Several landslides also occurred near this site during 1996-1997 (Baum and others, 2000), and one occurred nearby in late November or early December 2001 (fig. 2). The 45-m-high bluff consists of a layer of glacial advance outwash sand overlying glaciolacustrine silt (Minard, 1985). The contact between the outwash and silt is transitional, but the lower two-thirds of the bluff is predominantly silt. Interlayering of sand and silt allow perched water tables to exist locally as evidenced by seeps exposed by the landslide (fig. 2). The instruments were installed on a small bench about 10-15 $\mathrm{m}$ below the top of the bluff that appears to be part of a landslide deposit derived from a steep scarp several meters to the south. The sandy soil at the Everett site locally contains sufficient clay and silt to interfere with electronic measurement of water content.

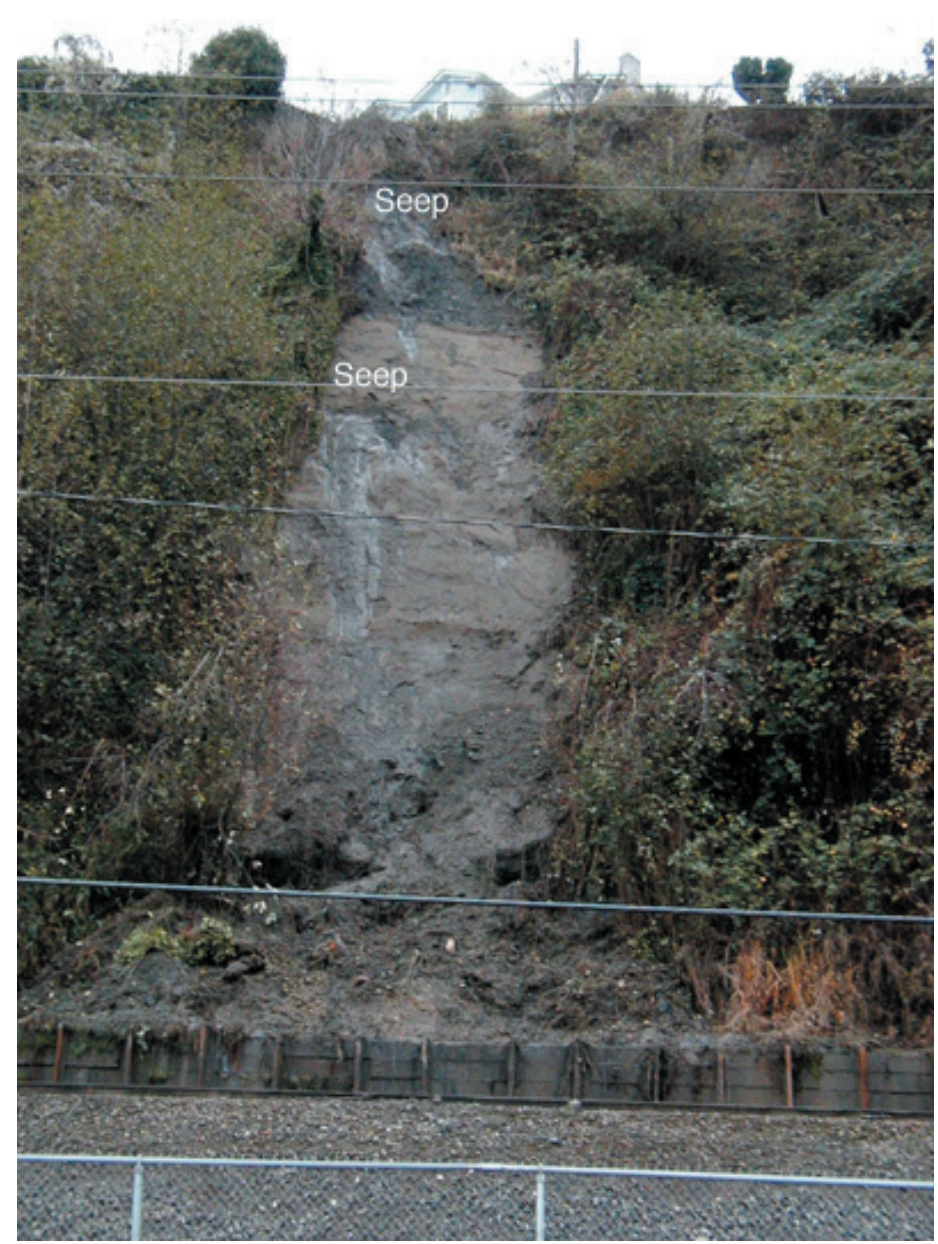

Figure 2. Photograph (view to south, taken December 5, 2001) of landslide that occurred between November 29 and December 5, 2001, about 200 m east of the Everett monitoring site. Rail bed of the BNSF Railway is shown in the foreground. Seeps indicated near east (left) edge of landslide scar are evidence of localized perching and lateral flow of water deeper within the bluff.
Calibration of the water-content reflectometers used at the site degrades with increasing clay content. As a result, the absolute values of our water-content measurements at Everett are less accurate than at the Edmonds site. However, relative changes throughout a season are still indicative of the timing and relative degree of soil wetting. After the first season of measurement, we moved the water-content instruments a short distance to soil that was less clayey to improve the accuracy of our measurements.

\section{Methods}

Our near-real-time field-data collection system at each site consists of commercially available geotechnical and environmental sensors connected to a field datalogger that is equipped with a radio for data transmission. The data are relayed over a commercial line-of-site radio network based in Kent, Washington, where the network operator places the raw data on an Internet server. Computers at USGS offices in Golden, Colorado, retrieve the data by hourly File Transfer Protocol (FTP) download, reduce and graph the data, and copy the graphs to a web server, which provides access to graphs of the most recent data in near real time.

\section{Field Instrumentation and Data Collection}

A field datalogger at each site (Campbell Scientific, Inc. model CR10X) reads the sensors on a regular schedule. The measurement interval is hourly for the current instrument configuration, but 1-second measurement intervals with 15minute or hourly recording intervals were tried previously when piezometers were in use. The dataloggers normally record hourly, but they have been programmed to record precipitation and other data on 15-minute intervals during times of high precipitation ${ }^{1}$. Regardless of the time interval, recording data triggers radio transmission of the most recent data. Although the datalogger hardware and operating system have proven reliable, occasional changes to instrumentation have required revision of the datalogger programs that have resulted in downtime ranging from an hour to a few days.

Solar panels are used to power the Everett site and AC current from a BNSF signal box powers the Edmonds site. A voltage regulator modulates the voltage input to a deep-cycle, 100 Amp-Hour, marine battery that stores power at each site. The battery, in turn, provides 12-volt DC input to the datalogger and peripherals. Battery voltage at Edmonds has remained stable and allowed nearly continuous data acquisition over the past 3 years. The distance from the nearest BNSF signal box and cost of a commercial power line made solar power the most affordable option for powering the Everett site. Solar power at Everett has been reliable during the spring, summer, and early fall, but

\footnotetext{
${ }^{1}$ Recording on 15 -minute intervals is triggered by 0.1 inch (in.) (2.54 millimeter, $\mathrm{mm}$ ) or more precipitation per hour and continues for 4 hours after precipitation becomes less than 0.1 in. $(2.54 \mathrm{~mm})$ during a 1-hour period.
} 
unreliable during the winter. The 12 -volt marine batteries used at the site have discharged sufficiently 1-2 times each winter to cause outages and data loss ranging from a few days to several weeks. The bluff shades the 40-watt solar panel in the morning, so the solar panel receives only afternoon sun. When the solar panel has full sun it produces 3A current; if it has full sun for at least 5 hours per day it produces an average 24-hour current of $625 \mathrm{~mA}$, but only about $125 \mathrm{~mA}$ during December and January when it receives only an hour of direct sunlight. At the end of the first year of operation, the power draw was $420 \mathrm{~mA}$, due in part to a faulty radio $(180 \mathrm{~mA})$ and in part to a DC-DC power converter (200 mA) that was used with the piezometers (Dale Smith, Meteor Communications, Inc., written commun., 2002). Changing the DC-DC converter to switched $12 \mathrm{~V}$ operation substantially reduced power requirements. However, even after removal of the piezometers and DC-DC converter in 2003, the battery discharged at least twice during the 2003-2004 winter season. Meteor Communications replaced the radio in 2004 in an attempt to further reduce power consumption. However, the battery subsequently discharged again on November 22, 2004.

Instrumentation at the two sites has changed several times since initial installation in September and October 2001. The original instrumentation at each site consisted of a rain gauge, three soil-water reflectometers, a soil-temperature probe, and three shallow ( $<2-\mathrm{m}$-deep) piezometers. Table 1 outlines the instrument configuration at each site as it has changed over time. Changes to instrumentation have been made because of failed or malfunctioning instruments and the addition of sensors needed to improve the range or quality of observations, such as the addition of tensiometers at Edmonds in 2002 to document conditions in unsaturated soils. Observation of shallow piezometers ceased in October 2003 as we replaced them with additional tensiometers. A new type of soil-water instrument, a borehole water-content profiler that measures soil wetness at multiple depths as great as $2 \mathrm{~m}$, also was installed at the Edmonds site in October 2003 to replace the water-content reflectometers. Lack of AC power made similar upgrades impractical at the Everett site. The following paragraphs describe the instrumentation in use since September 2001.

\section{Piezometers}

The piezometers consisted of 19-mm-diameter PVC tubes equipped with water-pressure sensors and inserted in shallow hand-auger borings. Where possible, the borings were advanced to the depth of a silt layer or other low-permeability zone where water might perch during the rainy season. The tubes were slotted at the bottom to allow entry of water, and electronic waterpressure transducers ${ }^{2}$ were inserted to the bottom of the tubes

\footnotetext{
${ }^{2}$ Initially, three Global Water model W300 vented electronic strain-gauge water pressure transducers were installed at Everett. Micron Electronics sealed electronic strain-gauge water-pressure transducers model MP102B15A were used at Edmonds and later at Everett.
}

to measure changing water pressure at the bottom of the hole. Piezometers at the Everett site sampled depths ranging from 107 to 116 centimeters $(\mathrm{cm})$ and those at Edmonds sampled depths ranging from 123 to $165 \mathrm{~cm}$. Slug tests (Bouwer and Rice, 1976; Bouwer, 1989) conducted in late May 2002 indicated that the soil surrounding the piezometer tips had hydraulic conductivity values ranging from $6.2 \times 10^{-5}$ to $1.1 \times 10^{-7}$ meters per second $(\mathrm{m} /$ $\mathrm{s})$, consistent with published values for outwash sands and silts from the Seattle area (Savage and others, 2000). During a few visits to the site during the winter 2001-2002 rainy season, we found little evidence of water in the piezometers. The bottom 1 $\mathrm{cm}$ of some of the transducers was wet, but we could not confirm that any water was standing at the bottom of the piezometer tube. If perched water tables existed at either of the monitoring sites, they were so ephemeral or localized that they could not be detected using the piezometers. Several pressure transducers had to be replaced over the 3-year period as shown in table 1 . The primary difficulties were with drift and noise. The transducers also were sensitive to temperature fluctuations. Although the transducers indicated what appeared to be positive pressures at times, attempts to correct for barometric and temperature fluctuations were only partially successful; consequently any possible isolated periods of perched water-table rise may not have been detected. Because of these difficulties, the piezometer data are not reliable and, therefore, not included in this report.

\section{Precipitation Gauges}

Each site originally was equipped with an 8-inch-diameter tipping-bucket rain gauge calibrated to 0.01 inch $(0.254 \mathrm{~mm})$ of rainfall per tip. The gauges have required cleaning at least once a year to remove accumulated debris. In September 2003, we added a second rain gauge at each site to provide redundancy in case one gauge became clogged or otherwise malfunctioned.

\section{Water-Content Reflectometers}

Water-content reflectometers (Campbell Scientific Model CS615) use time-domain reflectometry to measure soil bulk dielectric constant, which varies with the volumetric water content of a soil (reported here as percent of total soil volume). Clay content and electrical conductivity of the soil also affect the dielectric constant; thus, the calibration of the reflectometers must account for these effects (Campbell Scientific, Inc., 1996). These sensors have a pair of $30-\mathrm{cm}$-long rods that are inserted into the soil at the depth of measurement. At the time this report was written, the Everett site was equipped with three watercontent reflectometers that were buried at depths of 24, 39, and $50 \mathrm{~cm}$. These reflectometers have functioned reliably since May 2002. We installed the water-content reflectometers by digging a pit and pushing the reflectometer rods into the side of the pit either horizontally or subparallel to the sloping ground surface. The reported depth of measurement is the vertical distance from the ground surface to the center of the rods. Watercontent reflectometers also were used at the Edmonds site until September 2003 when they were replaced with the water-content profilers in order to provide measurement over a greater range 
Table 1. Changes to instrument configuration at each site since monitoring began in October 2001.

[A soil-temperature probe was used continuously at each site since monitoring began in October 2001. The following abbreviations are used in the headings and table: RG, rain gauge; WCR, water-content reflectometer; P, piezometer with pore-pressure transducer; T, tensiometer; BWC, borehole water-content sensor (profiler). A pore-pressure transducer matching those installed in shallow opentube piezometers was used to provide barometric corrections, denoted by " $\mathrm{B}$ " in the piezometer column. Number of instruments functioning (f), as indicated by measurements within the normal operating range, out of total installed (i) denoted by f/i.]

\begin{tabular}{|c|c|c|c|c|c|c|}
\hline \multicolumn{7}{|c|}{ Edmonds Site } \\
\hline Date & RG & WCR & $\mathbf{P}$ & $\mathbf{T}$ & BWC & Comment \\
\hline Oct. 10,2001 & 1 & $1 / 3$ & 3 & 0 & 0 & $\begin{array}{l}\text { Data transmission began, WCR at } 41 \mathrm{~cm} \text { and } 29 \mathrm{~cm} \\
\text { not working }\end{array}$ \\
\hline Nov. 28, 2001 & 1 & $2 / 3$ & $3+\mathrm{B}$ & 0 & 0 & Added barometer, WCR at $41 \mathrm{~cm}$ started working \\
\hline Late Dec. 2001 & 1 & $1 / 3$ & $3+\mathrm{B}$ & 0 & 0 & WCR at $41 \mathrm{~cm}$ stopped working \\
\hline Feb. 14, 2002 & 1 & $3 / 3$ & $3+\mathrm{B}$ & 0 & 0 & $\begin{array}{l}\text { Replaced } 15-\mathrm{lbf} / \mathrm{in}^{2} \text { pressure transducer at surface } \\
\text { with } 50-\mathrm{lbf} / \mathrm{in}^{2} \text { model, to match down-hole } \\
\text { instruments. WCR at } 41 \mathrm{~cm} \text { started working again. }\end{array}$ \\
\hline Mar. 2002 & 1 & $1 / 3$ & $3+\mathrm{B}$ & 0 & 0 & $\begin{array}{l}\text { WCR at } 69 \mathrm{~cm} \text { worked intermittently and eventually } \\
\text { stopped }\end{array}$ \\
\hline May 30, 2002 & 1 & $2 / 2$ & $3+\mathrm{B}$ & 0 & 0 & $\begin{array}{l}\text { Nonfunctioning WCR at } 29 \mathrm{~cm} \text { removed, working } \\
\text { WCR relocated to } 45 \text { and } 97 \mathrm{~cm} \text { (WCR at } 45 \mathrm{~cm} \\
\text { produced no useful data before Aug. 15). Exchanged } \\
\text { pressure transducers for a different model and } \\
\text { conducted slug tests. Cleaned rain gauge }\end{array}$ \\
\hline Aug. 15, 2002 & 1 & $2 / 3$ & $3+\mathrm{B}$ & 0 & 0 & $\begin{array}{l}\text { Cleaned RG and reattached cable, WCR at } 45 \\
\text { and } 97 \mathrm{~cm} \text { working, Replaced WCR at } 29 \mathrm{~cm} \text {, but } \\
\text { new one did not work either. }\end{array}$ \\
\hline Nov. 17, 2002 & 1 & $2 / 3$ & $3+\mathrm{B}$ & 2 & 0 & $\begin{array}{l}\text { Exchanged surface pressure transducer (B), added } \\
\text { two tensiometers at } 48 \mathrm{~cm} \text { and } 88 \mathrm{~cm} \text {, checked water- } \\
\text { level transducer calibration at various water depths, } \\
\text { installed new WCR at } 12 \mathrm{~cm} \text {, WCR at } 45 \mathrm{~cm} \text { quit } \\
\text { working }\end{array}$ \\
\hline Jan. 4, 2003 & 1 & $2 / 3$ & $3+\mathrm{B}$ & 2 & 0 & Rain gauge became clogged. \\
\hline Sep. 25,2003 & 2 & $0 / 0$ & 0 & 12 & $16 / 16$ & $\begin{array}{l}\text { Removed WCR and pressure transducers, cleaned rain } \\
\text { gauge and added a second. Added two groups of six } \\
\text { tensiometers and two borehole water content profilers } \\
\text { (BWC) having eight sensors each. }\end{array}$ \\
\hline Dec. 19, 2003 & 2 & $0 / 0$ & 0 & 12 & $8 / 16$ & $\begin{array}{l}\text { Cable break caused BWC at lower site to stop } \\
\text { working }\end{array}$ \\
\hline Jan. 22, 2004 & 2 & $0 / 0$ & 0 & 12 & $16 / 16$ & Repaired cable to lower BWC \\
\hline
\end{tabular}


Table 1. Changes to instrument configuration at each site since monitoring began in 0ctober 2001-Continued

\begin{tabular}{|c|c|c|c|c|}
\hline \multicolumn{5}{|r|}{ Everett Site $^{1}$} \\
\hline Date & RG & WCR & $\mathbf{P}$ & Comment \\
\hline Oct. 12,2001 & 1 & $1 / 3$ & 3 & Data transmission began, WCR at $25 \mathrm{~cm}$ and $46 \mathrm{~cm}$ not working \\
\hline Nov. 02, 2001 & 1 & $1 / 3$ & 3 & Lost data transmission, weak battery \\
\hline Nov. 29, 2001 & 1 & $2 / 3$ & $3+\mathrm{B}$ & $\begin{array}{l}\text { Added pressure transducer at surface for barometric corrections, replaced } \\
\text { battery, WCR at } 46 \mathrm{~cm} \text { began working }\end{array}$ \\
\hline Jan. 7, 2002 & 1 & $2 / 3$ & $3+\mathrm{B}$ & Replaced battery \\
\hline May 28, 2002 & 1 & $3 / 3$ & $3+\mathrm{B}$ & $\begin{array}{l}\text { Repositioned WCR at } 24,39 \text {, and } 50 \mathrm{~cm} \text { depths, conducted slug tests in } \\
\text { piezometers }\end{array}$ \\
\hline Nov. 16, 2002 & 1 & $3 / 3$ & $3+\mathrm{B}$ & Recharged battery \\
\hline Nov. 25, 2003 & 1 & $3 / 3$ & $3+\mathrm{B}$ & Replaced battery \\
\hline Feb. 26, 2003 & 1 & $3 / 3$ & $3+\mathrm{B}$ & Replaced battery \\
\hline Oct. 15,2003 & 2 & $3 / 3$ & 0 & Removed piezometers and barometer \\
\hline Dec. 1,2003 & 2 & $3 / 3$ & 0 & Replaced battery \\
\hline Jan. 21, 2004 & 2 & $3 / 3$ & 0 & Replaced battery \\
\hline
\end{tabular}

${ }^{1}$ Dates of battery failures and data loss at Everett: November 1-29, 2001; December 23, 2001-January 7, 2002; November 21-25, 2002; January 9-February 26, 2003; November 22-December 1, 2003; December 23, 2003-January 21, 2004.

of depths. Three reflectometers were in use at Edmonds from September 2001 to September 2003, but only one or two worked at any given time. Some of the problem may have resulted from faulty cabling or connections or long cable runs rather than the instruments themselves. In the three seasons of monitoring, at least two water-content reflectometers failed and had to be replaced.

\section{Water-Content Profilers}

Since late September 2003, the Edmonds site has been equipped with two Sentek EnviroSMART TM water-content profilers that have sensors at eight different depths, ranging from 20 to $200 \mathrm{~cm}$. Each water-content profiler is installed in a vertical 56.5-mm-diameter PVC tube. The two instruments are located about 6-8 $\mathrm{m}$ apart in holes about mid-height on the bluff (fig. 1B and 1C). These sensors measure soil capacitance, which varies with volumetric soil-water content (reported as percent of total soil volume), which we will refer to as soil wetness (Hillel, 1982). Water-content profiler units have been in use for only about a year, but they have functioned reliably so far. A broken cable connection between power supply and the lower watercontent profiler resulted in loss of data from December 19, 2003, to January 22, 2004.

\section{Tensiometers}

Since late September 2003, the Edmonds site has been equipped with two arrays or nests of tensiometers with six tensiometers per array. The tensiometers (Soil Moisture Corp. Model \#2100F) are equipped with current transducers that can measure positive and negative (suction) pore pressures and are installed at depths ranging from 20 to $150 \mathrm{~cm}$. The tensiometers are designed for measuring suctions in the range 
from 0 to $100 \mathrm{kPa}$ (equivalent to suction head of 0 to $10.2 \mathrm{~m}$ of water); however, the tips usually dry out at about 6-7 $\mathrm{m}$ of suction. In the event that the water table rises above the tip of the tensiometer, it also can register positive pressures. Tensiometer tips at the Edmonds site are buried at depths ranging from 20-150 $\mathrm{cm}$; the maximum positive pore pressure that could occur at such depths is unlikely to exceed hydrostatic pressure $(14.7 \mathrm{kPa}$ at $150 \mathrm{~cm}$ depth). The tensiometers have performed reliably during the wet season, but they require regular maintenance when the soil begins to dry. The tensiometer tubes must be filled with deaired water to measure pore pressure or matric suction. The tensiometer tubes are filled at the end of the dry season, and they function reliably until the soil begins to dry again during the spring.

\section{Soil-Temperature Sensor}

A thermistor (Campbell Scientific, Model 107-L) is buried several centimeters below the ground surface at each site to measure soil temperature. The soil-temperature measurements are used to make corrections to other measurements and to detect if and when the ground becomes frozen.

\section{Telemetry}

Meteor Communications, Inc, (Meteorcomm) provides data telemetry for the two monitoring sites under contract to BNSF. Data are transmitted from the site via a line-of-site radio network to Meteorcomm's offices in Kent, Wash., where the data are saved to a computer server. Data transmission is triggered every time the datalogger saves data to its final storage area. A USGS computer in Golden, Colo., retrieves the data hourly from the server by File Transfer Protocol (FTP). During beginning stages of monitoring, minor problems with telemetry resulted from incompatibilities between the radios and the data-logger memory configuration or data-logger programs. Minor changes to radio and datalogger programs subsequently resolved these difficulties. During 2003-04, some minor difficulties occurred at the Everett site in which the datalogger occasionally reported a "time-out" error, and the radio stopped transmitting. Rebooting of the field data-collection system restored normal operation (Dale Smith, Meteor Communications, Inc., oral commun., 2004).

\section{Data Processing and Internet}

Final data processing occurs on a computer at USGS offices in Golden, Colo. Programs running on the USGS computer archive the data and prepare it for display on the Internet. Processing steps include (1) retrieving, sorting, and reformatting raw data from the Meteorcomm server, (2) reducing the data to convert voltage or other readings to engineering units, (3) computing representative daily values for use in long-term summaries, (4) plotting recent data in Portable Network Graphics (PNG) format for display on web pages, and (5) copying the results to a USGS web server. Processing relies on a combination of open-source software and USGS programs and scripts that can be implemented on a wide range of computer systems. Detailed description of the software and methods used is beyond the scope of this report.

During September and October 2003, we made major improvements to software and procedures for processing and displaying the data on the Internet. Other minor changes and improvements have occurred since monitoring began in 2001. These changes have resulted from changes in the field instrumentation, computer operating systems upgrades, computer maintenance or replacement, software improvements, and movement of the web pages to different USGS web servers. These various changes have caused web-page outages that have lasted from hours to days or a few weeks but resulted in little actual data loss. The changes have resulted in more stable and reliable data processing and decreased downtime of our web page since October 2003. Since June 2002, our web pages have been served by a USGS web server system that has redundant servers at various locations across the United States.

\section{System Reliability}

The data collection systems at the Edmonds and Everett sites were designed for scientific data collection and not as an early warning system. Any monitoring system is subject to occasional outages, but a brief review of difficulties experienced with the systems deployed at Edmonds and Everett may assist in design and operation of future shallow landslide data collection or early warning systems so as to reduce outages and improve data quality. Perhaps the most serious difficulty in this monitoring has been repeated loss of power at the Everett site that has resulted in loss of data for extended periods during the rainy season. Use of AC power, particularly in areas of low winter sunlight, seems critical for uninterrupted operations. Use of AC power also allows more frequent sampling rates for pore pressure or other quantities that can fluctuate rapidly during storms. Solar power could be used successfully at sites where AC power is unavailable provided solar panels can be placed in locations that receive several hours of sunlight even during mid-winter, but routine replacement (or rotation and recharging) of batteries also might be needed to prevent outages.

Our data and experience indicate that rain gauges and lowmaintenance, water-content profilers provide reliable indicators of conditions that can result in occurrence of shallow landslides. Tensiometric observations can provide important additional insight to conditions that affect the timing of landslide activity because pore pressures can change more rapidly in response to precipitation and barometric fluctuations than soil wetness. For example, compression of entrapped air beneath a wetting front can cause a transient pore pressure increase long before the wetting front reaches the depth of the observed pressure change (Freeze and Cherry, 1979). Tensiometers provide more rapid response to changes in conditions than water-content sensors, but they increase the maintenance requirements of a monitoring system. Tensiometers perform reliably provided they are refilled regularly and protected from freezing. At the Edmonds site, we protected the tensiometers by inverting a Styrofoam ice chest 
of the ice chest. Shallow, open-tube piezometers have provided little, if any useful data at the Edmonds and Everett coastal bluff sites, because the water table apparently never rose above the level of the sensors despite efforts to construct the piezometers so that they sampled the soil directly above a low-permeability layer that was capable of perching water. Therefore, piezometers should be reserved for locations known to have a perennial or persistent seasonal water table.

Although we have made significant improvements to the stability of our data-processing systems and Internet display of data since the beginning of the project, external events such as power outages or local computer network maintenance can still result in interruption of automated processing and display of the data. Deployment of redundant computers, preferably at separate locations, seems to be the simplest way to improve reliability of data-processing capabilities for this system.

\section{Summary of Data and Results}

Observations of long-term and short-term variation of precipitation, soil wetness, and pore pressure are vital to understanding the relations between precipitation and landslide occurrence. Although details vary between the two sites and from year to year, long-term trends indicate seasonal wetting of the soil shortly after the beginning of the rainy season in November or December; soil wetness remains elevated until late spring when rainfall amounts decrease and the soil gradually dries until the beginning of the next rainy season. During the rainy season and after the soil had wetted, short-term increases in soil moisture occurred within hours after significant rainfall. After the rain stopped and the wetting front had passed any given observation point (sensor), soil wetness gradually declined over several days to prestorm levels. At a site, soil wetness at some depths is higher throughout the year than at others. These long-term differences in absolute value of the soil wetness at different depths are indicative of spatial variations in porosity and other properties of the soil as well as slight differences between individual sensors, which were not individually calibrated for soil at the sites. Our description and analysis of soil wetness data in succeeding paragraphs focus primarily on the changes through time, rather than absolute value of the soil wetness, in order to identify flow directions and characterize subsurface water movement in response to rainfall.

\section{1-2002 Rainy Season}

Baum and others (2002a, 2002b) summarized results of the 2001-2002 monitoring season at Edmonds and Everett. Measurements made during the winter, rainy season of 20012002 indicated wetting fronts propagating downward through the soil at both sites.

\section{Edmonds}

Volumetric water-content measurements made at depths of 41 and $69 \mathrm{~cm}$ during the winter rainy season of 2001-2002 show evidence of downward propagating wetting fronts that varied with rainfall intensity, duration, and antecedent soil wetness. Three sensors were installed in October 2001 (table 1), but only those at 41 and $69 \mathrm{~cm}$ worked, and they produced incomplete records with only partial overlap (fig. 3A). The observed soil wetness at $41 \mathrm{~cm}$ typically was greater than at $69 \mathrm{~cm}$, a difference that is consistent with local variations in properties of the soil. The soil remained relatively dry through mid-November 2001 at $69 \mathrm{~cm}$ depth; no data are available at $41 \mathrm{~cm}$ before 12:00 p.m. on November 29 (fig. 3A, 3B). Following $40 \mathrm{~mm}$ of rain from November 19-22, soil wetness at $69 \mathrm{~cm}$ began to increase at about 1:00 a.m. on November 22 (fig. 3B). Additional rain over the next week raised soil wetness about 4 percent by the time wetting peaked at 9:00 a.m. on December 2; soil wetness then gradually decreased about 1 percent over the next several days. Data at $41 \mathrm{~cm}$ depth indicates that the soil wetness peaked at or before 12:00 p.m. on November 29, nearly 3 days before the peak at $69 \mathrm{~cm}$ (fig. 3B). The delayed peak at $69 \mathrm{~cm}$ depth relative to the peak at $41 \mathrm{~cm}$ is consistent with downward movement of the water.

After wetting at the end of November, soil wetness remained elevated throughout the winter and spring. Periods of relatively intense rainfall produced sharp wetting fronts that rapidly raised the soil wetness by 1-3 percent in December, January, and March. After the rain stopped, soil wetness gradually declined over several days to prestorm levels. The increase in soil wetness that resulted from a given storm event was greater at $41 \mathrm{~cm}$ than at $69 \mathrm{~cm}$ (fig. 3A), and soil wetness peaked several hours earlier at $41 \mathrm{~cm}$ than at $69 \mathrm{~cm}$. For example, $62 \mathrm{~mm}$ of rain that fell December 12-16 raised soil wetness about 3 percent at $41 \mathrm{~cm}$ and 1.2 percent at $69 \mathrm{~cm}$ (fig. 3C). Most $(51 \mathrm{~mm})$ of the rain fell from 9:00 a.m. on December 15 to 12:00 a.m. on December 17. The soil wetness at $41 \mathrm{~cm}$ started rising at 1:00 a.m. on December 14, accelerated on December 15, and peaked at 12:00 a.m. on December 17, coincident with the end of the storm. The soil wetness at $69 \mathrm{~cm}$ started rising at 3:00 p.m. on December 14 and peaked at 6:00 a.m. on December 17. Soil wetness gradually declined over the next 2 weeks during which we recorded only a few millimeters of precipitation (fig. 3A). In contrast, $32 \mathrm{~mm}$ of rain that fell over 3 days (January $6-8,2002$ ) produced a diffuse (rounded peak) wetting front at $69 \mathrm{~cm}$ that peaked about 9:00 a.m. on January 9; soil wetness gradually declined during the next 2 weeks when relatively little rain fell (fig. 3A). Another smaller storm in March caused a smaller, more gradual increase in soil wetness at depth (fig. 3A).

\section{Everett}

We installed three water-content reflectometers at Everett, but only two of them produced usable data during the 2001-2002 rainy season. Only one sensor (74 cm depth) worked from midOctober until early November 2001 and produced an intermittent record; after the battery was replaced in late November, the sensors at depths 46 and $74 \mathrm{~cm}$ produced fairly complete records until we moved them at the end of May 2002 (fig. 4A). The soil wetness at Everett appears to be significantly higher than at Edmonds. However, this difference is more apparent than real 

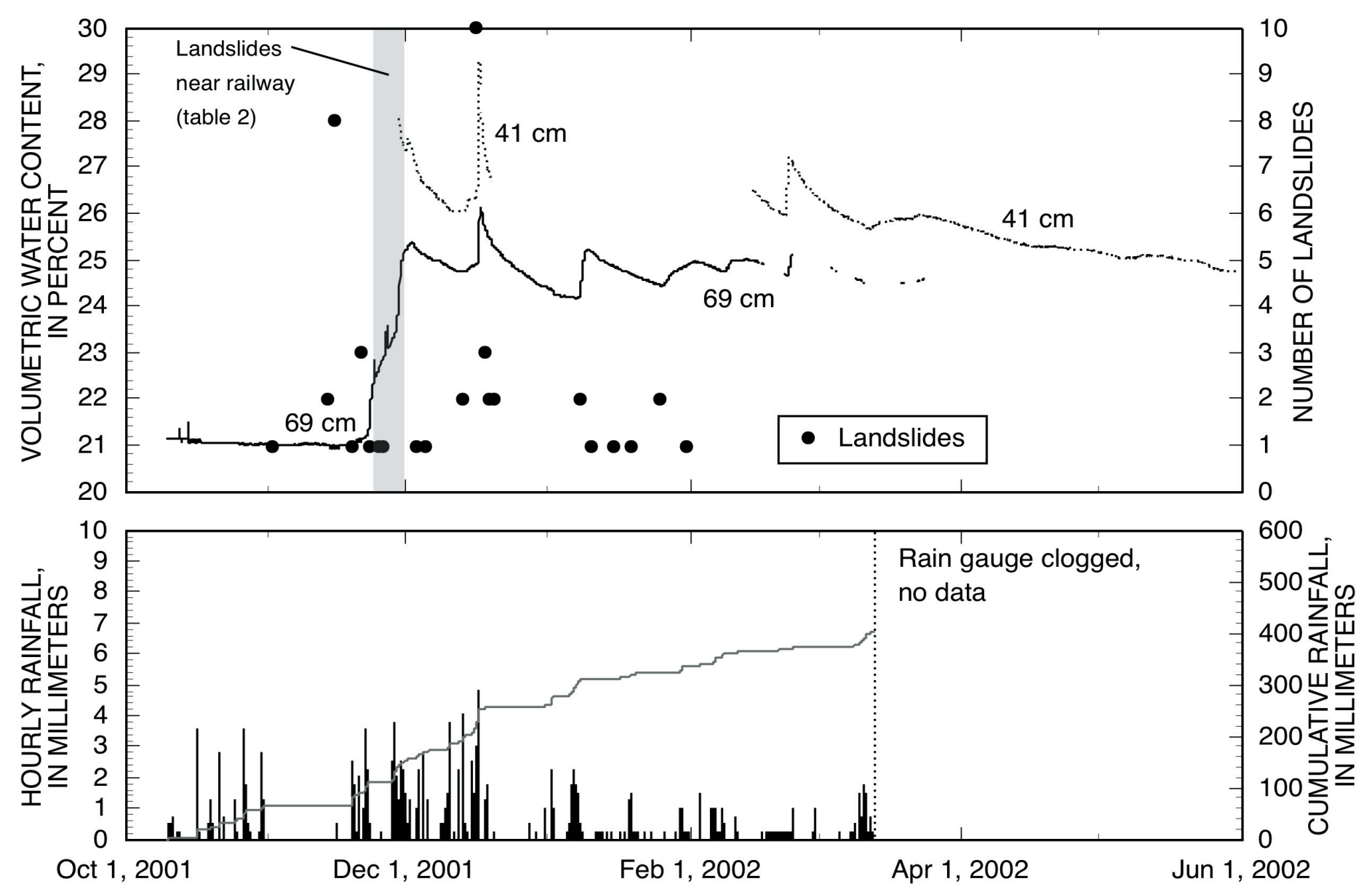

Figure 3. Hourly precipitation and soil wetness measured by water-content reflectometers at 41 and $69 \mathrm{~cm}$ depth at the Edmonds site, A. Observations from October 10, 2001 to May 31, 2002, dates and numbers of landslides in Seattle (Chleborad, 2003; Chleborad, A.F., U.S. Geological Survey, written commun., 2004) shaded area indicates timing of landslides near the BNSF rail corridor between Seattle and Everett listed in table 2. B. Detailed observations from November 27 to December 3, 2001, C. Detailed observations from December 12 to December 18, 2001. 

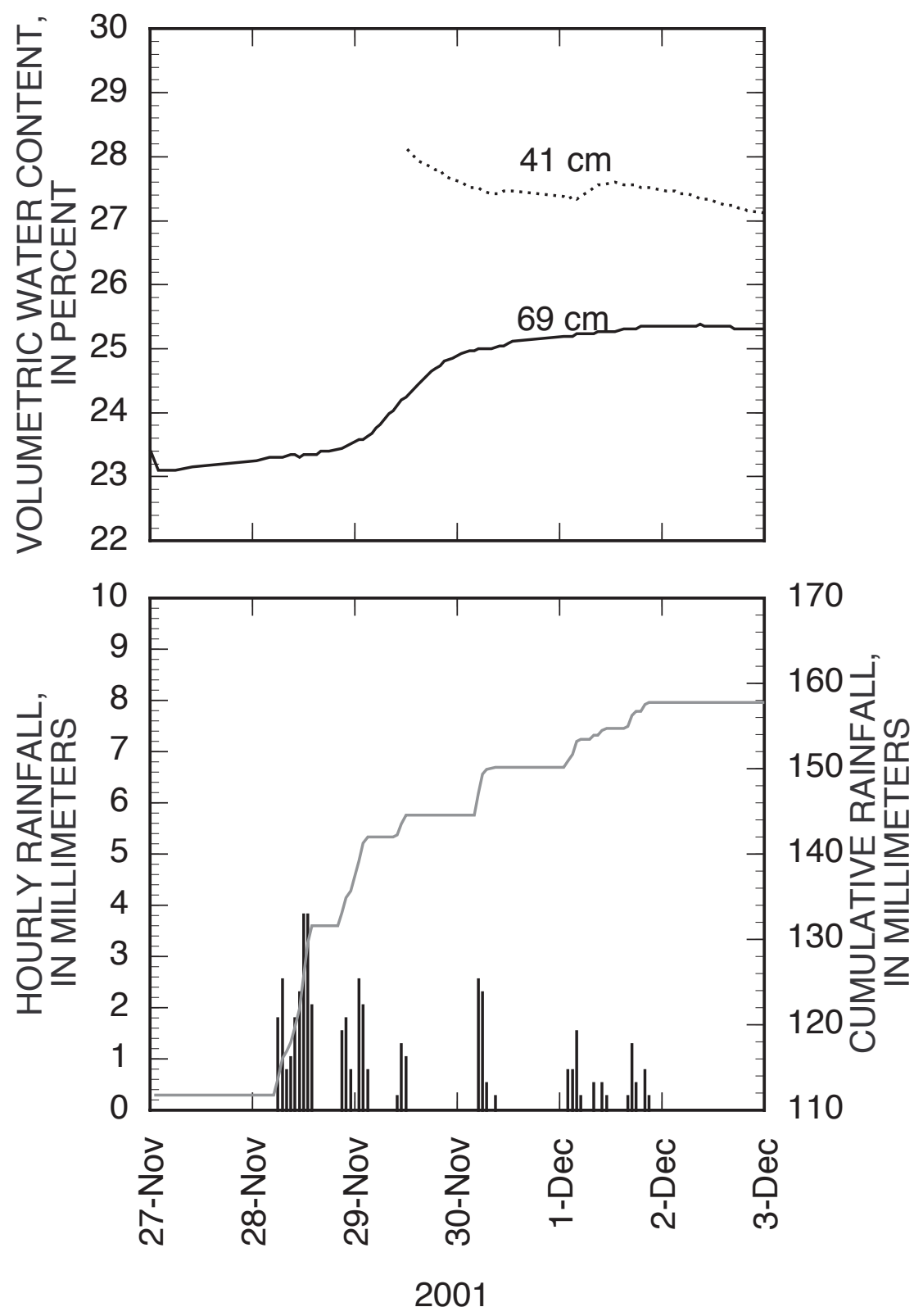

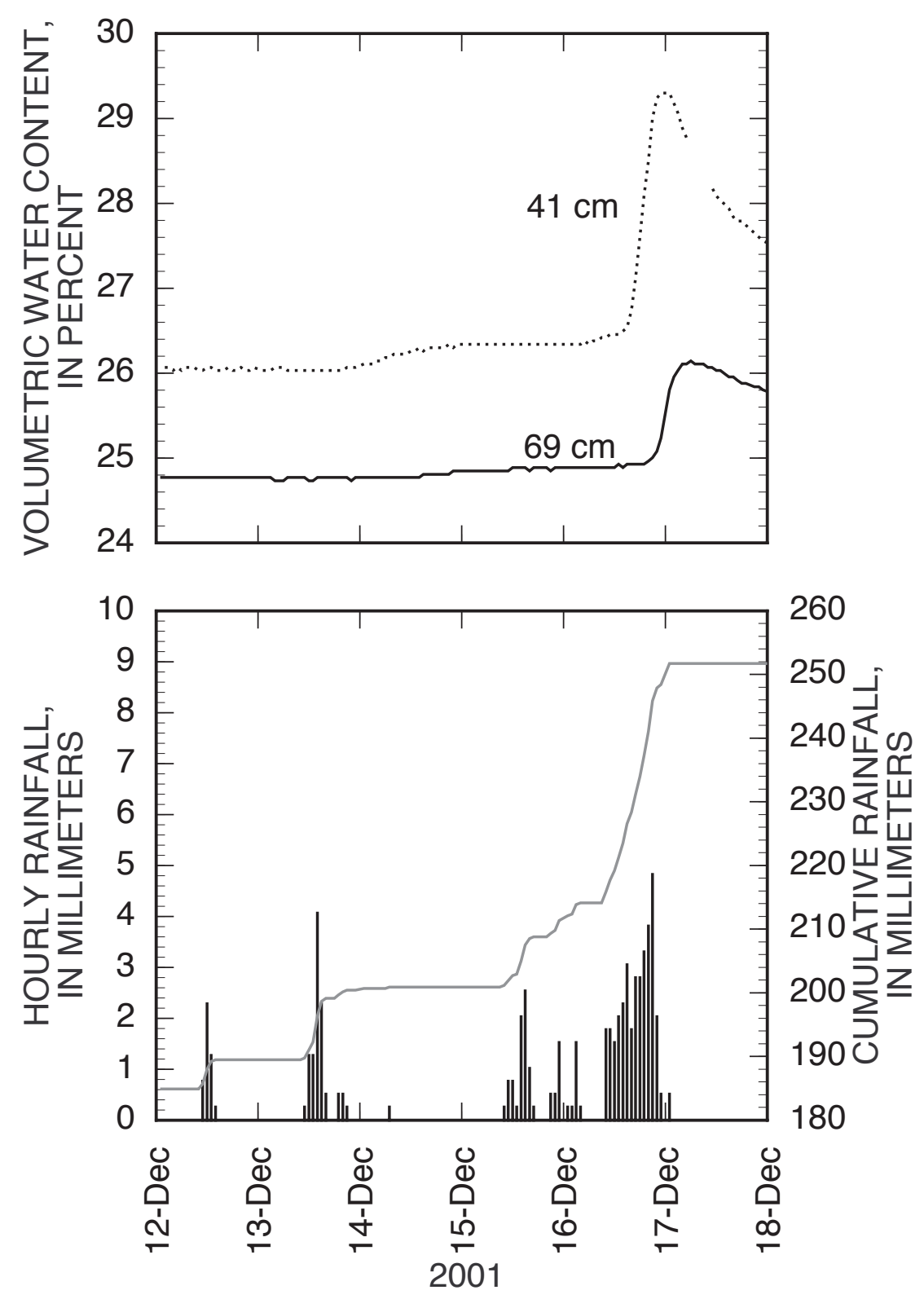


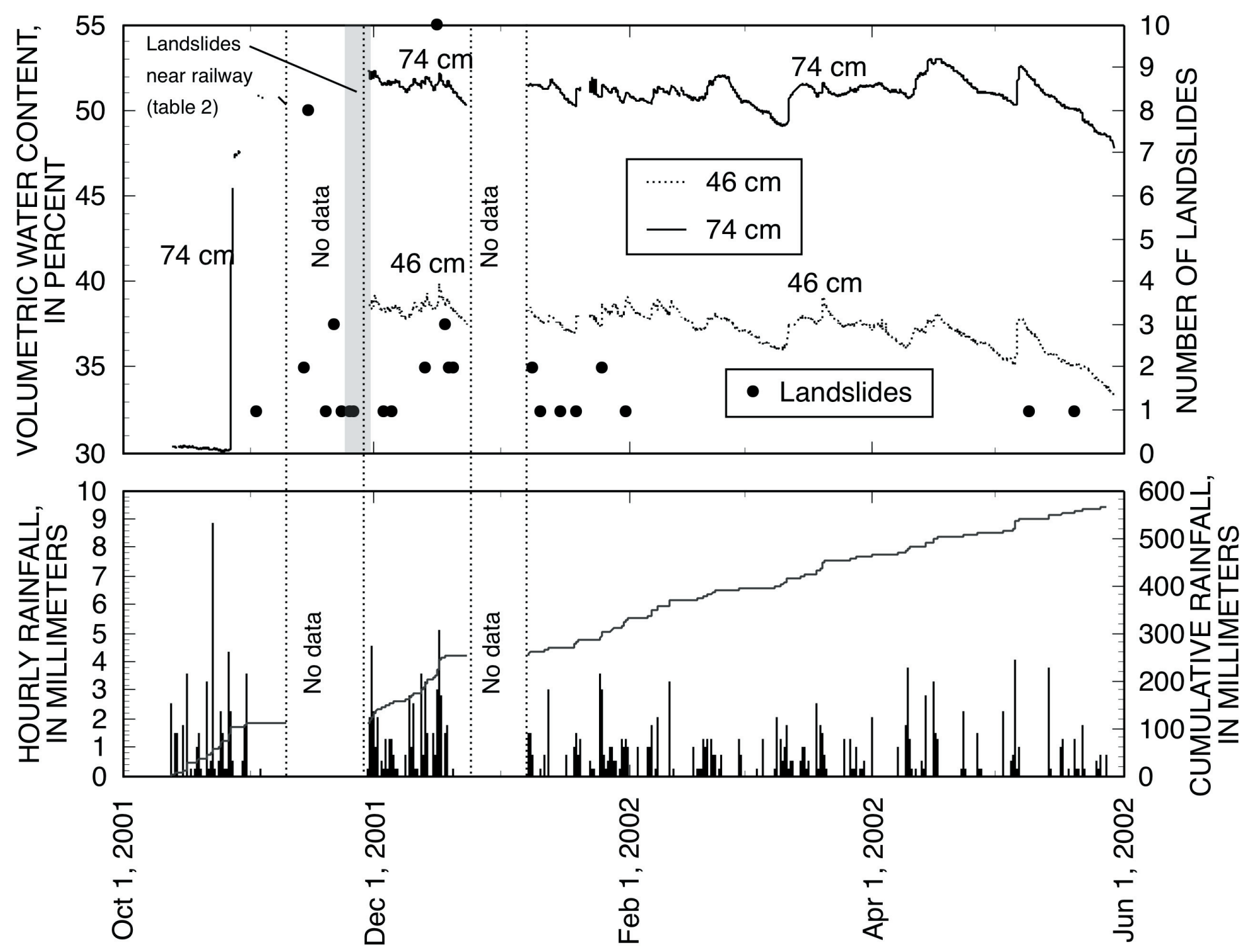

Figure 4. Hourly precipitation and soil wetness measured by water-content reflectometers at 46 and $74 \mathrm{~cm}$ depth at the Everett site, A. Observations from October 10, 2001 to May 29, 2002, dates and numbers of landslides in Seattle (Chleborad, 2003; Chleborad, A.F., U.S. Geological Survey, written commun., 2004) shaded area indicates timing of landslides near the BNSF rail corridor between Seattle and Everett listed in table 2. B. Detailed observations from December 12 to December 20, 2001, C. Detailed observations from February 15 to February 27, 2002, D. Detailed observations from May 2 to May 10, 2002. 

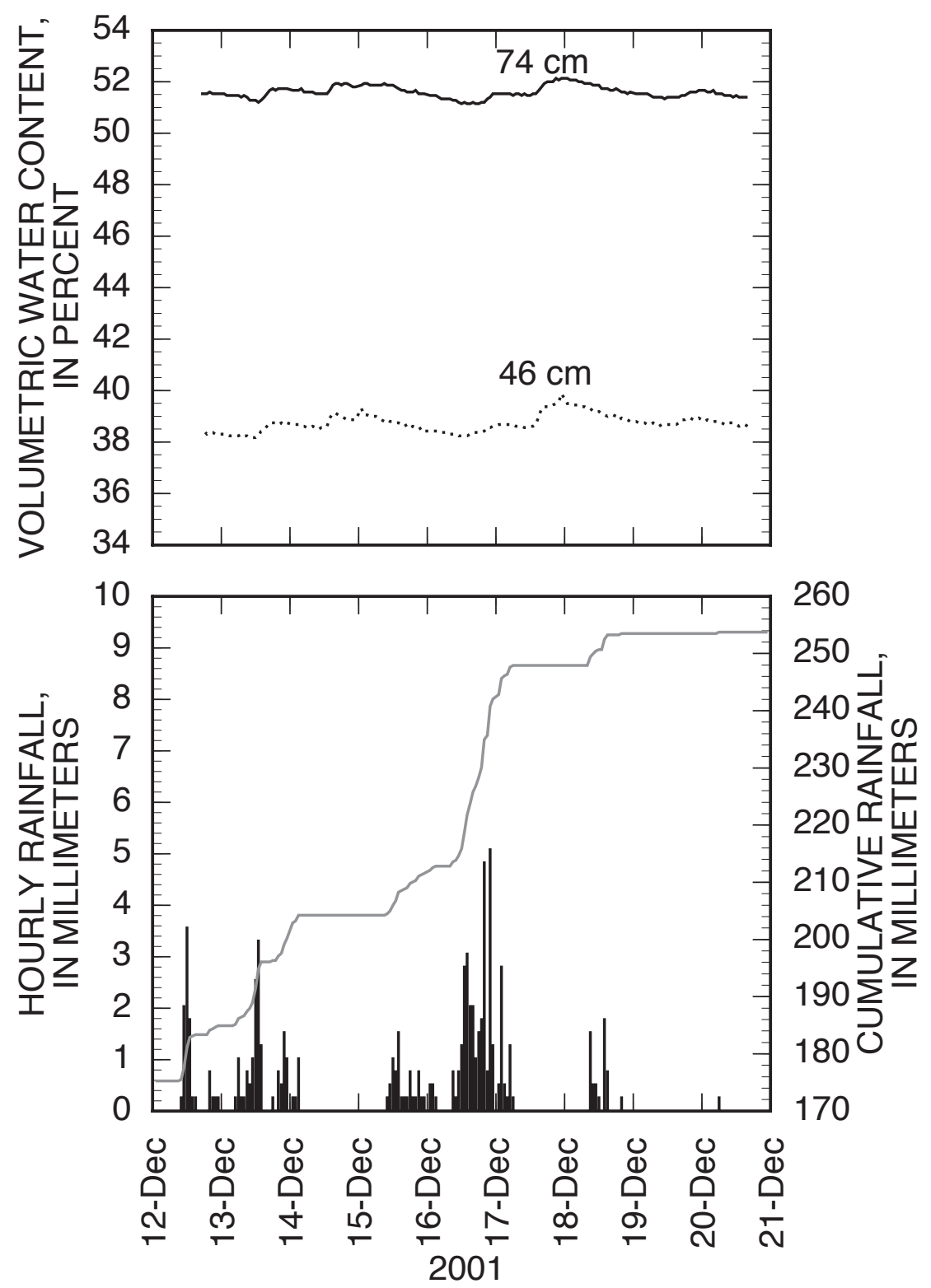

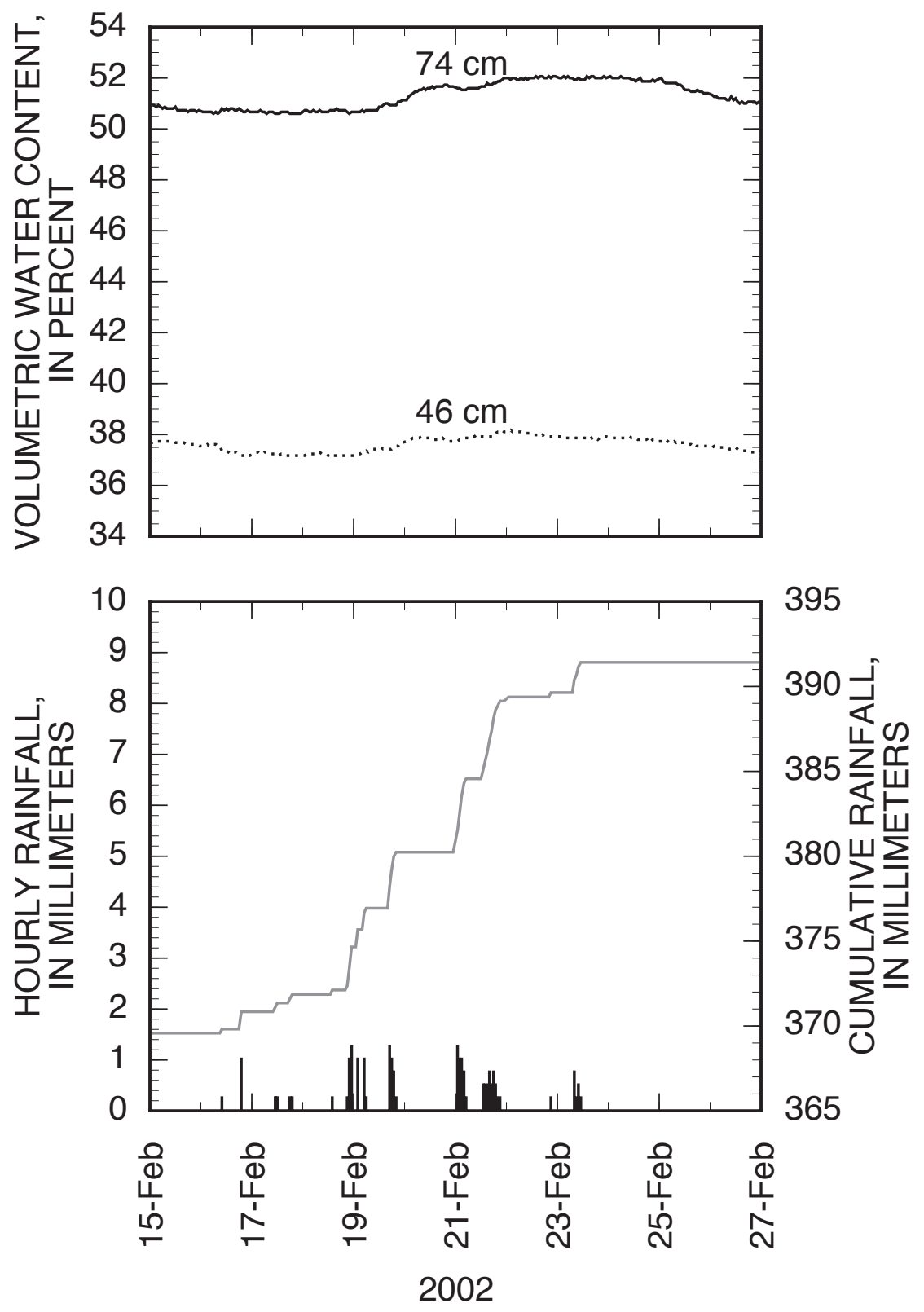

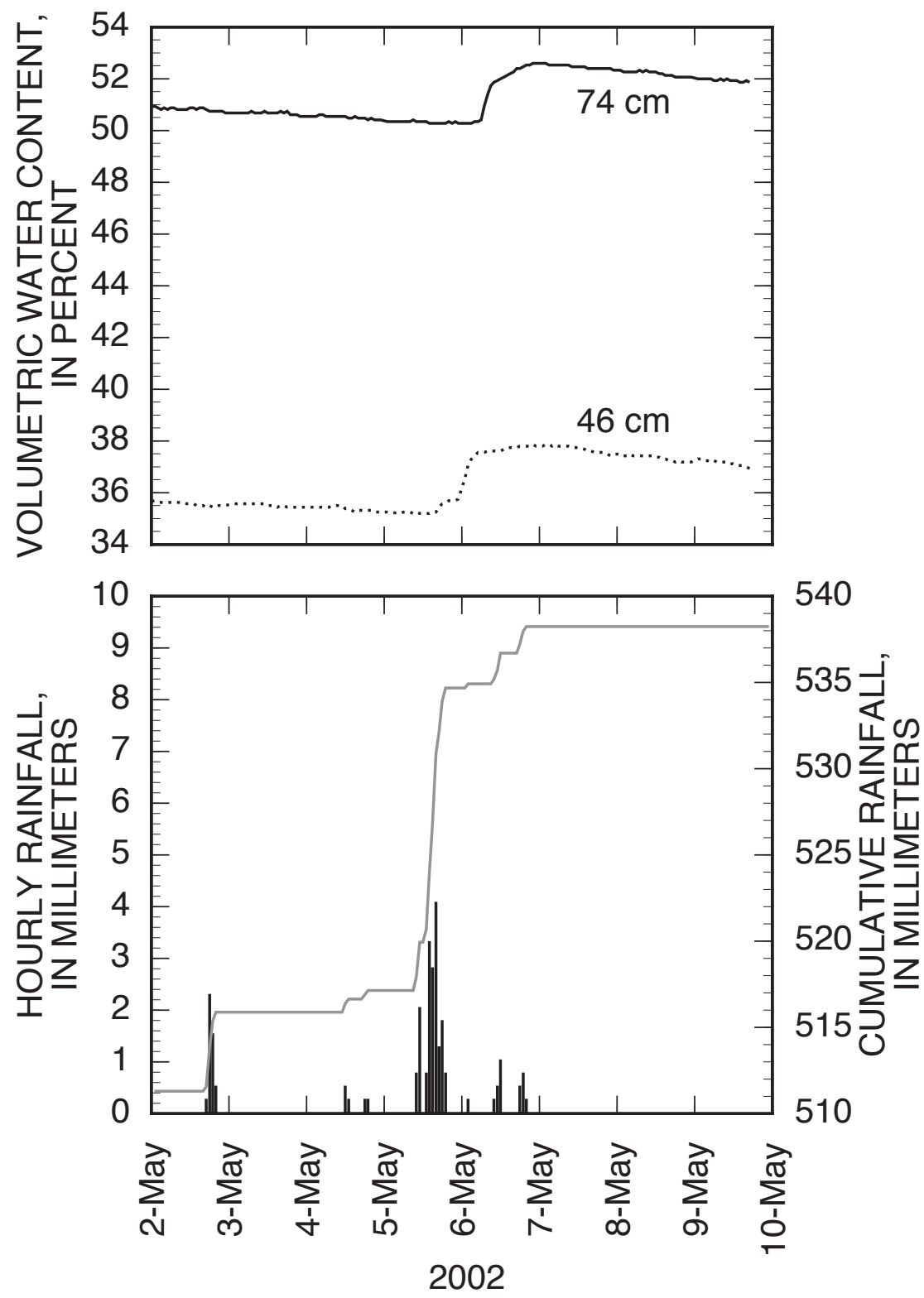
because the high clay content of soils at the Everett site affects its dielectric constant. The reported values of soil wetness are approximate; we applied calibration factors for soils that have a high electrical conductivity to account approximately for the clay content, but the specific calibration for soil at the site would be needed to accurately measure the soil wetness. The longterm average soil wetness at $46 \mathrm{~cm}$ is about 15 percent lower than at $74 \mathrm{~cm}$, and this long-term difference results from some combination of differences in porosity and clay content of soils surrounding the two water-content reflectometers and minor differences in the two reflectometers. Regardless of the actual soil wetness at Everett, the measurements accurately portray relative changes in soil wetness through time.

Measurements indicate that the soil at $74 \mathrm{~cm}$ depth had been relatively dry before late October 2001; no data are available for the sensor at $46 \mathrm{~cm}$ before late November. The soil at $74 \mathrm{~cm}$ wetted abruptly following $100 \mathrm{~mm}$ of rain that accumulated during the second half of October at Everett (fig. 4A). The soil wetness rose from 30.2 percent at 3:00 a.m. on October 27 to 47.2 percent by 2:00 a.m. on October 28 and then gradually to 47.5 percent at 4:00 a.m. on October 29. By 1:00 a.m. on November 1, the soil wetness had increased to 50.7 percent. After November 1, soil wetness at $74 \mathrm{~cm}$ remained within 2 percent of this value and soil wetness at $46 \mathrm{~cm}$ though lower, remained within 2 percent of its November 1 value through mid- or late April 2002. One landslide occurred near the Everett site sometime in late November or early December (fig. 2), and several shallow landslides also occurred in the Seattle area from mid-November to mid-December (fig. 3A; Chleborad, 2003).

After November 1 until mid-May, intense rainfall produced sharp wetting fronts that rapidly raised the soil wetness by 1-2 percent at Everett, and low-intensity rainfall produced more gradual increases in soil wetness (fig. 4A). For example $38 \mathrm{~mm}$ of rain that fell between 9:00 a.m. on December 15 and 12:00 p.m. December 16 raised soil wetness by 1.6 percent at $46 \mathrm{~cm}$ and 1 percent at $74 \mathrm{~cm}$ depth; soil wetness peaked at 11:00 p.m. shortly after the end of intense rainfall (fig. 4B). Low-intensity rainfall continued until about 6:00 a.m. on December 17, but it was insufficient to raise or maintain soil wetness at depth, and water levels declined steadily during the ensuing days of no rain. From mid-January to mid-February, several smaller storms that each produced about $20 \mathrm{~mm}$ of rain within 24 hours raised soil wetness by about 1 percent at $46 \mathrm{~cm}$ and roughly 0.5 percent at $74 \mathrm{~cm}$ (fig. 4A). Lower intensity rainfall amounting to $12 \mathrm{~mm}$ in three and one-half days caused a smaller, less peaked rise in soil wetness of about 1 percent from February 19 to February 21. Additional more intense rain on February 21 and 22 resulted in only a slight additional rise in soil wetness on February 21 and 22. Soil wetness peaked about 10 p.m. on February 21 at 46 $\mathrm{cm}$ and at about 2:00 p.m. on February 22 at $74 \mathrm{~cm}$ (fig. 4C). A similar event in March produced a slightly larger rise (fig. 4A). Finally, an intense storm on May 5 and 6 produced $25 \mathrm{~mm}$ of rain and caused about 2 percent increase in soil wetness at 46 and $74 \mathrm{~cm}$ (figs. 4A and 4D). Within the resolution of the data, soil wetness peaked simultaneously at 46 and $74 \mathrm{~cm}$ about 10:00 p.m. on May 6, 2002; however, figure 4D clearly shows that the period of most intense rainfall preceded the most rapid rise at $46 \mathrm{~cm}$ by several hours, which in turn preceded the most rapid rise at 74 $\mathrm{cm}$ by several hours. Observations at Everett are consistent with downward movement of wetting fronts after rainfall.

\section{2-2003 Season}

\section{Edmonds}

Soil wetness at Edmonds declined throughout the spring and summer of 2002, rose gradually in the fall, and remained high throughout the winter. The sensor at $41 \mathrm{~cm}$ recorded declining soil wetness from mid-March through the end of May 2002 (fig. 3A). We replaced two of the water-content reflectometers on May 30 (table 1) with limited success; the shallow sensors stopped working, and a sensor at $97 \mathrm{~cm}$ recorded gradually declining soil wetness from May 30 until early October, when soil wetness leveled off at a minimum steady value until midDecember 2002 when soil wetness began to rise (fig. 5A). Limited data indicate that storms in October and November raised the soil wetness slightly at $45 \mathrm{~cm}$ depth. A new sensor at $12 \mathrm{~cm}$ depth (installed November 17, 2002) along with the sensor at $97 \mathrm{~cm}$ recorded significant rewetting of the soil during mid-December 2002. Precipitation on several successive days from December 9 to December 19 raised soil wetness of the soil by several percent at depths of 12 and $97 \mathrm{~cm}$ (fig. 5B). The wetting front passed $12 \mathrm{~cm}$ by December 17 at about the same time wetting began at $97 \mathrm{~cm}$ depth, where soil wetness increased gradually until January 2, 2003, and then increased abruptly on January 2 and 3. This 4-percent increase over two and onehalf weeks resulted from $140 \mathrm{~mm}$ of rain that fell December 9-19 and December 25-January 3 (fig. 5B). The soil at $97 \mathrm{~cm}$ remained relatively wet from January 3 until about the end of March. The soil at $12 \mathrm{~cm}$ depth followed a similar pattern, remaining relatively wet from December 17 to about April 27, 2003; soil wetness declined steadily thereafter. The largest daily precipitation amount recorded during the season was 36 $\mathrm{mm}$ on December 14, while the soil was still wetting; accurate daily precipitation data after January 3, 2003, are unavailable (fig. 5A, 5B, 6A, 6B). However, measured rainfall amounts at Everett give a rough indication of rainfall after January 2003; several smaller storms occurred during January, February, March, and April of 2003 (fig. 7A). At Edmonds, these rainstorms temporarily raised the soil wetness and pore-water pressures several times during January, February, and March 2003 (fig. 5A, 5B, and 6). Response to rainfall clearly decreased with depth; soil wetness at $12 \mathrm{~cm}$ increased more abruptly and in response to smaller storms than at $97 \mathrm{~cm}$ (fig. 5A and $5 \mathrm{~B}$ ). Likewise, pressure head increased more abruptly at $48 \mathrm{~cm}$ than at $88 \mathrm{~cm}$ depth (fig. 6). Despite the increases in soil wetness and pore pressure, the rainfall amounts mid-December 2002 through the spring of 2003 usually were inadequate to trigger landslides as few were reported. A notable exception was the landslide that occurred on March 22, 2003, when soil wetness was at its highest during the season (fig. 3A). After April 27, soil wetness at $12 \mathrm{~cm}$ 


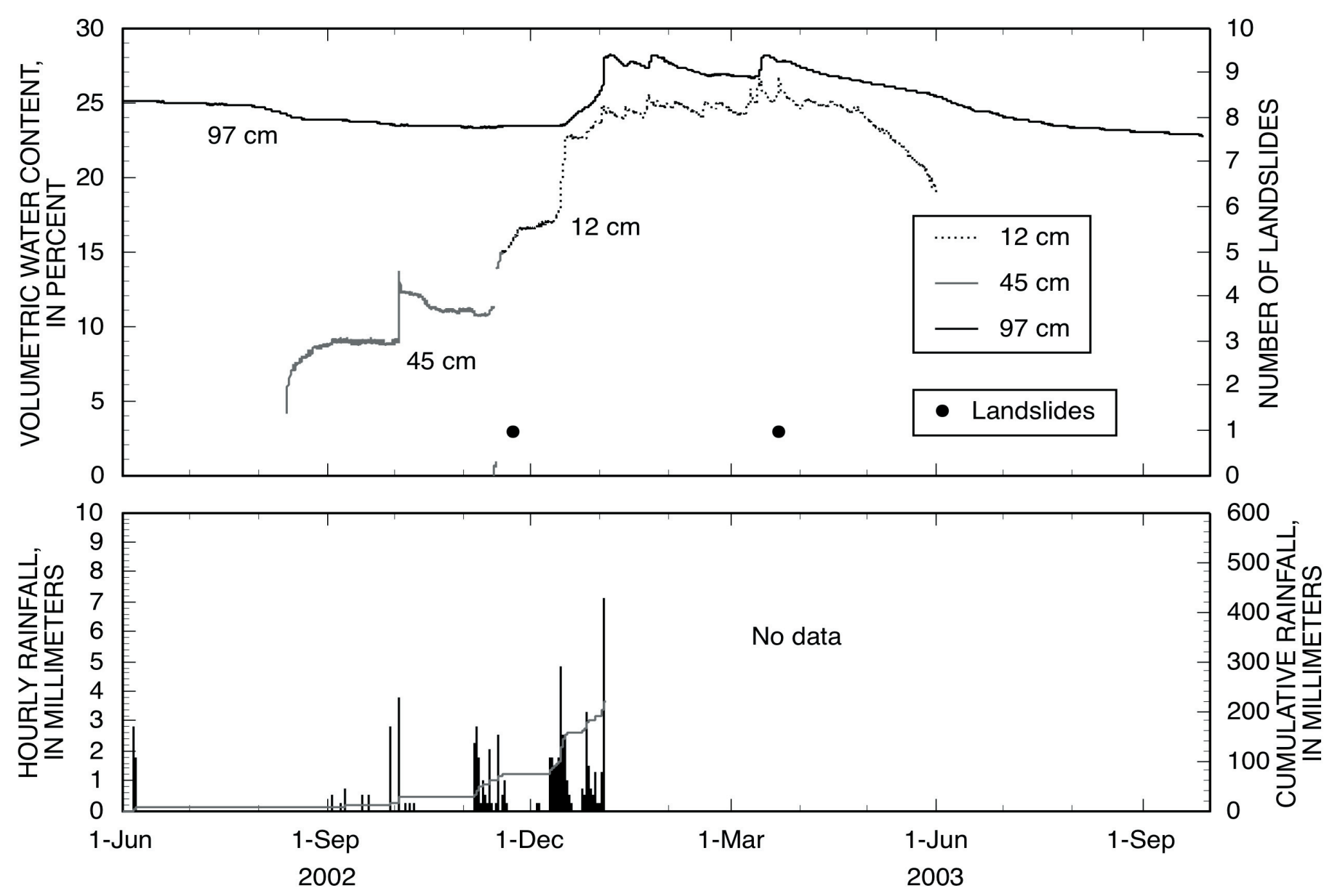

Figure 5. Hourly precipitation and soil wetness measured by water-content reflectometers at 12,45 , and $97 \mathrm{~cm}$ depth at the Edmonds site. At the end of May 2002, the reflectometers were moved from 41 and $69 \mathrm{~cm}$ depth to 45 and $97 \mathrm{~cm}$ depth, and the nonworking reflectometer was removed; a reflectometer was subsequently added at $12 \mathrm{~cm}$ depth during mid-November 2002. A. Observations from May 31, 2002, to September 28, 2003. B. Detailed observations from November 29, 2002 through February 16, 2003. 


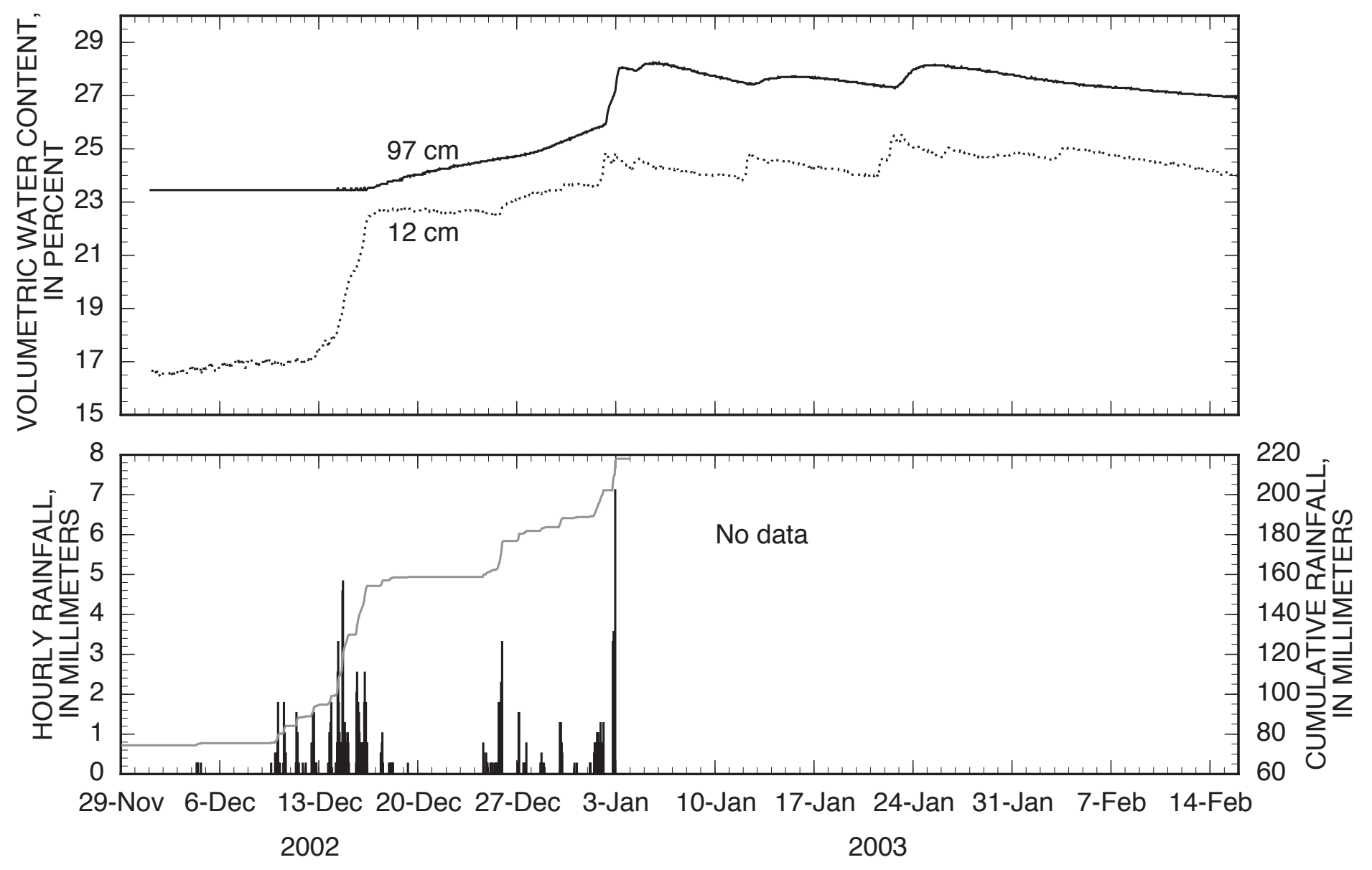




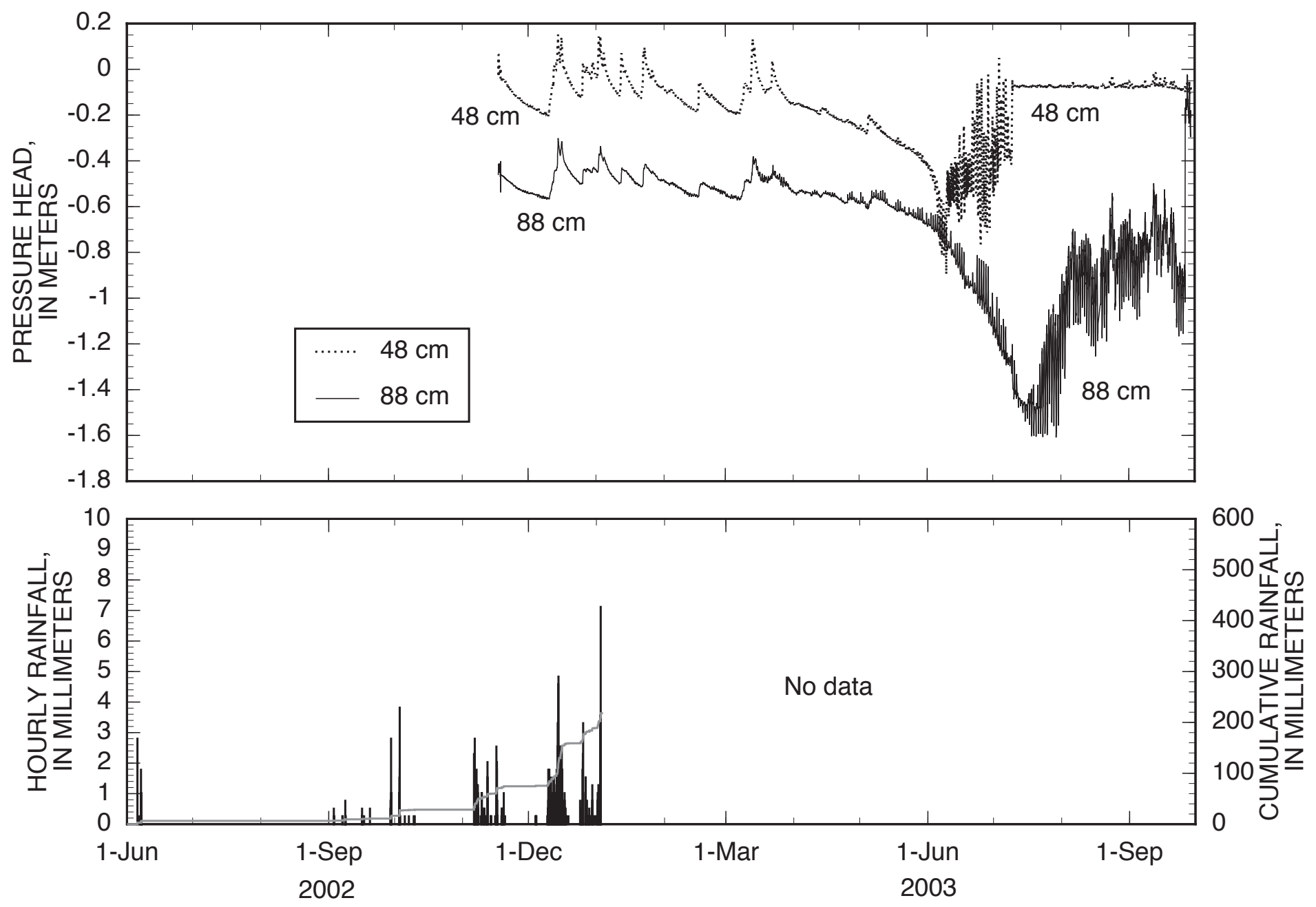

Figure 6. Hourly precipitation and pressure head measured by tensiometers installed during mid-November 2002 at 48 and $88 \mathrm{~cm}$ depth at the Edmonds site, A. From November 15, 2002, to September 28, 2003. Readings after June 1, 2003, became unreliable as the soil continued to dry because the tensiometers had not been refilled. B. Detailed observations from November 29, 2002, to February 16, 2003. 

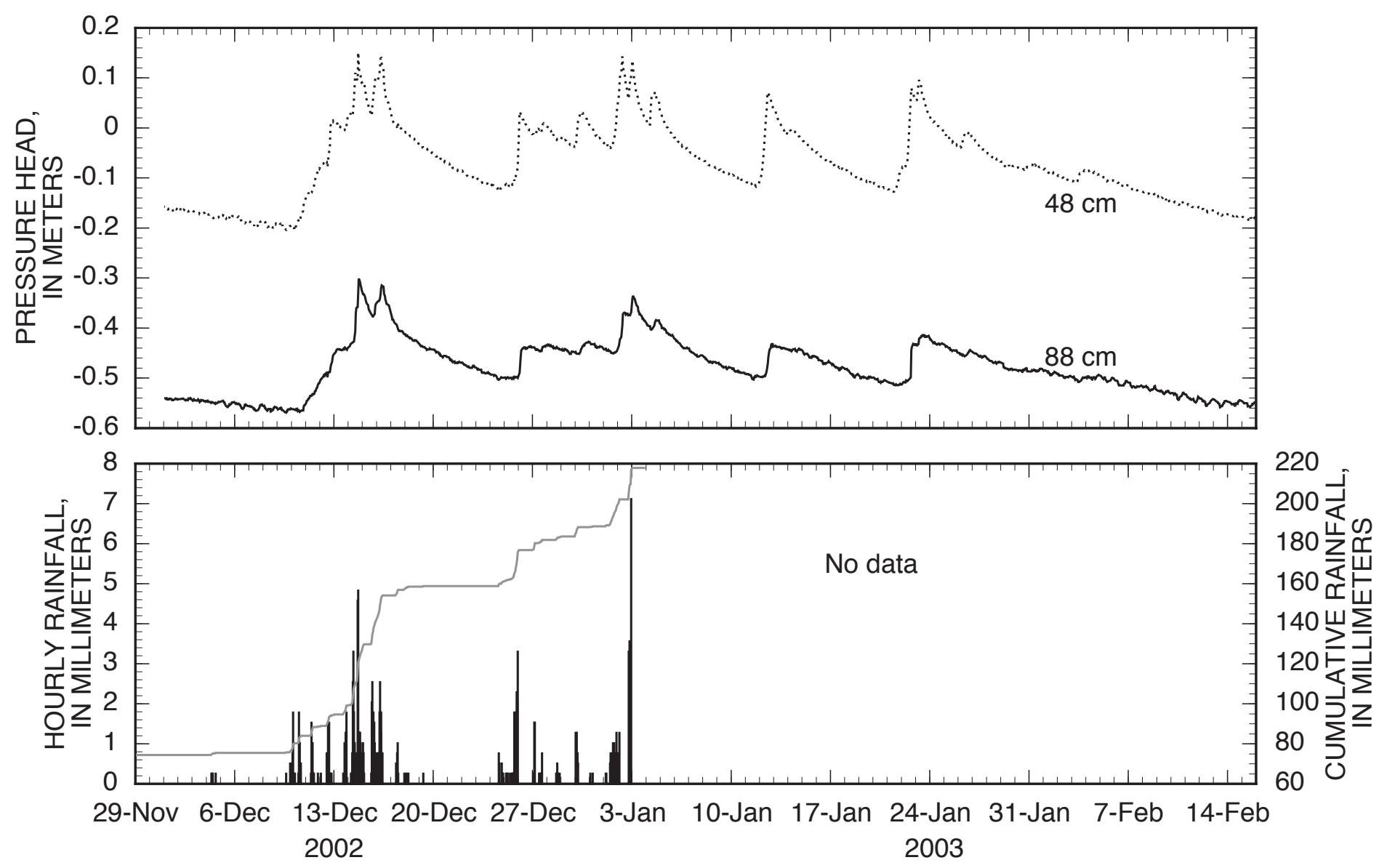
declined in a pattern similar to that observed during the spring of 2002. At $1 \mathrm{~m}$ depth, this decline started about a month earlier (March 28, 2003) than in 2002.

\section{Everett}

Our instruments at Everett recorded an overall pattern of summer drying followed by wetting of soil during the fall and relatively wet soil conditions, characterized by rapid increases during rainfall followed by more gradual declines throughout the winter. On May 28, 2002, we repositioned the water-content reflectometers at the Everett site to depths of 24,39 , and $50 \mathrm{~cm}$ (table 1). With the exception of a brief rise following a storm early in July, all three sensors recorded generally declining soil wetness from the end of May through the late August or early September when soil wetness attained a minimum steady value (fig. 7A). Precipitation in mid-October 2002 began rewetting the soil, and the soil wetness increased episodically in response to small storms in October and November. Precipitation on several successive days from December 9 to December 19 raised soil wetness by several percent at all three sensors (fig. 7A and $7 \mathrm{~B}$ ). Soil wetness at all three depths remained elevated until the end of April, and soil wetness generally increased by 1-3 percent at each depth following storms that individually produced 12 to $40 \mathrm{~mm}$ of rain. Magnitude of the response is greatest at 24 $\mathrm{cm}$ depth, intermediate at $39 \mathrm{~cm}$, and usually weakest at $50 \mathrm{~cm}$; peaks also are sharpest at $24 \mathrm{~cm}$ and most rounded at $50 \mathrm{~cm}$ (fig. 7B). Decreasing response with depth is consistent with downward flow of water from the ground surface. Timing of the increasing soil wetness in response to rain in December 2002 also is consistent with downward flow (fig. 7B); soil wetness at $24 \mathrm{~cm}$ began rising about 1:00 p.m. on December 10 and almost a day later at 39 and $50 \mathrm{~cm}$ (11:00 a.m. on December 11). Soil wetness rise during January-April 2003 commonly peaked 1-7 hours later at $50 \mathrm{~cm}$ than at $24 \mathrm{~cm}$.

\section{3-2004 Rainy Season}

\section{Edmonds}

During September 2003, we upgraded instrumentation at the Edmonds site to include two water-content profile probes that measure volumetric water content (soil wetness) at eight depths between 0.2 and $2 \mathrm{~m}$, two tensiometer nests with sensors at 6 depths between 0.2 and $1.5 \mathrm{~m}$, two rain gauges, and one soiltemperature probe (table 1). These upgrades were implemented to better define relations between soil wetness, pore pressure, and precipitation that were observed during the previous two seasons.

McKenna and others (2004) described results of monitoring during the 2003-2004 wet season. During October 2003, the soil was dry and wetting fronts moved slowly in response to rainfall as indicated by the increasing time lag between precipitation and peak soil wetness at increasing depth (fig. 8A, 8B, 8C, 8D, 8E, and $8 \mathrm{~F}$ ). In mid-October, record 24-hour rainfall (127.5 $\mathrm{mm}$ at the Seattle-Tacoma airport) produced a few shallow landslides and debris flows. Preexisting, very dry conditions (for example,
12 percent water and suction of $-1.2 \mathrm{~m}$ water at $0.8 \mathrm{~m}$ depth, fig. 8A, 9A) slowed movement of the wetting front at the Edmonds site. This storm produced $74.4 \mathrm{~mm}$ of rain in 32 hours at Edmonds, and the soil wetness at $2 \mathrm{~m}$ depth increased only 2-3 percent over 6 days (fig. 8C, 8F). As soil wetness increased throughout the winter season, pore pressure and soil wetness at depth responded much more rapidly to heavy rainfall (fig. 8 and 9). In mid-November $90.9 \mathrm{~mm}$ of rain fell in 29 hours resulting in a 2-4 percent increase in soil wetness at $2 \mathrm{~m}$ depth in only 1 day (fig. 8C and 8F). The rounded peaks at depths of $120 \mathrm{~cm}$ and greater for the mid-October storm compared with sharp peaks at the same depths for the mid-November storm clearly depict this difference in response between dry conditions at the beginning of monitoring and wet conditions from November 2003 through March 2004 (fig. 8B, 8C, 8E, and 8F). Sharp peaks at all depths, even at 120 and $150 \mathrm{~cm}$ depth, indicate that despite dry conditions, pore pressure changed rapidly in response to the midOctober rainfall as well as subsequent storms (fig. 9A, 9B, 9C, and 9D). Average prestorm pressure-head measurements show a difference of $\sim 0.2 \mathrm{~m}$ of water for shallow tensiometers and less than $0.1 \mathrm{~m}$ of water at depth between the early and late rainy season (fig. 9). Soil wetness at $2 \mathrm{~m}$ depth differs by 5 percent during the same period.

\section{Everett}

Monitoring at the Everett site showed a somewhat similar soilwetness history to that observed at Edmonds. On October 11, soil wetness began increasing at $24 \mathrm{~cm}$ in response to rainfall (fig. $10 \mathrm{~A}$ and 10B). Soil wetness at 39 and $50 \mathrm{~cm}$ began increasing on October 15 following additional rainfall. The October 20 storm that produced record-breaking 24-hour precipitation at SeattleTacoma Airport produced only $47 \mathrm{~mm}$ at Everett. Soil wetness increased abruptly at $24 \mathrm{~cm}, 39 \mathrm{~cm}$, and $50 \mathrm{~cm}$ on October 20-21 with the greatest increase, about 4 percent, occurring at $50 \mathrm{~cm}$ depth (fig. 10B). Smaller increases recorded at 24 and $39 \mathrm{~cm}$ on October 20-21 are consistent with time lag at depth, because soil wetness had increased incrementally at 24 and $39 \mathrm{~cm}$ after previous storms. The soil was dry before the storm, so the peaks were rounded compared to those observed from mid-December 2003 through early March 2004 (fig. 10A). Soil wetness rose episodically and gradually until November 18 and 19, when $83.6 \mathrm{~mm}$ of rain fell in 31 hours resulting in an abrupt, shortduration increase in soil wetness (fig. 10A). Average soil wetness remained high during the remainder of the rainy season, and soil wetness changed rapidly in response to rainfall from November 19 to late March. Soil wetness began to decline steadily in late March 2004. Several days of low-intensity precipitation at the end of May rewetted soil at Everett, resulting in a 5-7 percent increase in soil wetness at depths of 24 to $50 \mathrm{~cm}$ (fig. 10A).

\section{Landslide Activity}

Many landslides occurred in the Seattle area throughout the period of monitoring. A few were reported on coastal bluffs between Edmonds and Everett (fig. 1A, table 2), but many more were reported in Seattle (fig. 3A, 4A; Chleborad, 2003). Despite 


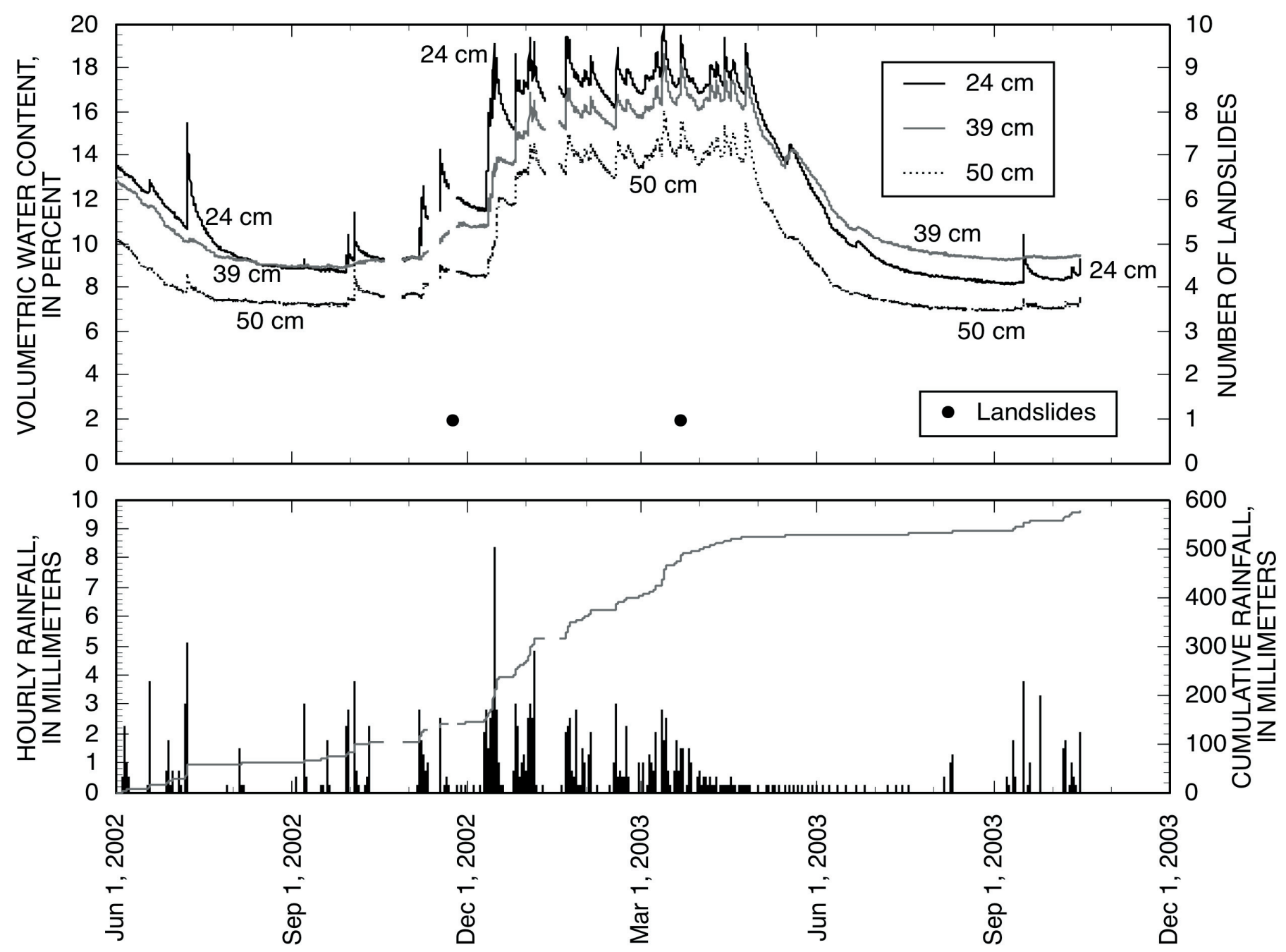

Figure 7. Hourly precipitation and soil wetness measured by water-content reflectometers at 24,39 , and $50 \mathrm{~cm}$ depth at the Everett site. The tensiometers were moved from their original location to depths of 24, 39, and $50 \mathrm{~cm}$ at the end of May 2002. A. From May 31, 2002, to October 15, 2003, gaps in curves indicate times of no data (October 18-28, 2002; November 10-16, 2002; November 21-25, 2002; January 10-17, 2003). B. Soil wetness from December 1, 2002 through April 30, 2003, gaps in curves indicate times of no data (January 10-17, 2003). Major ticks on horizontal axis indicate months, and minor ticks indicate weeks. 

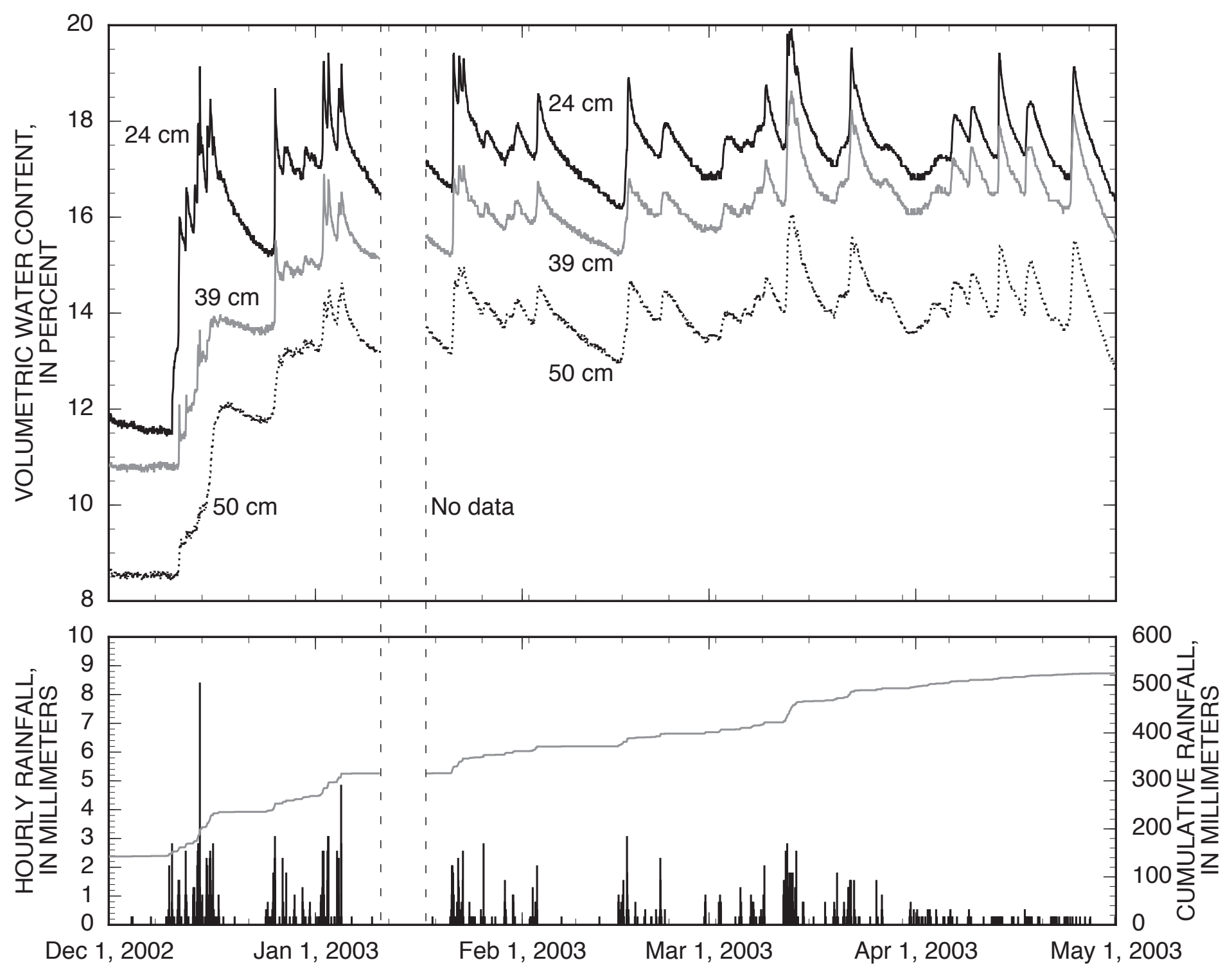
$8 \mathrm{~A}$
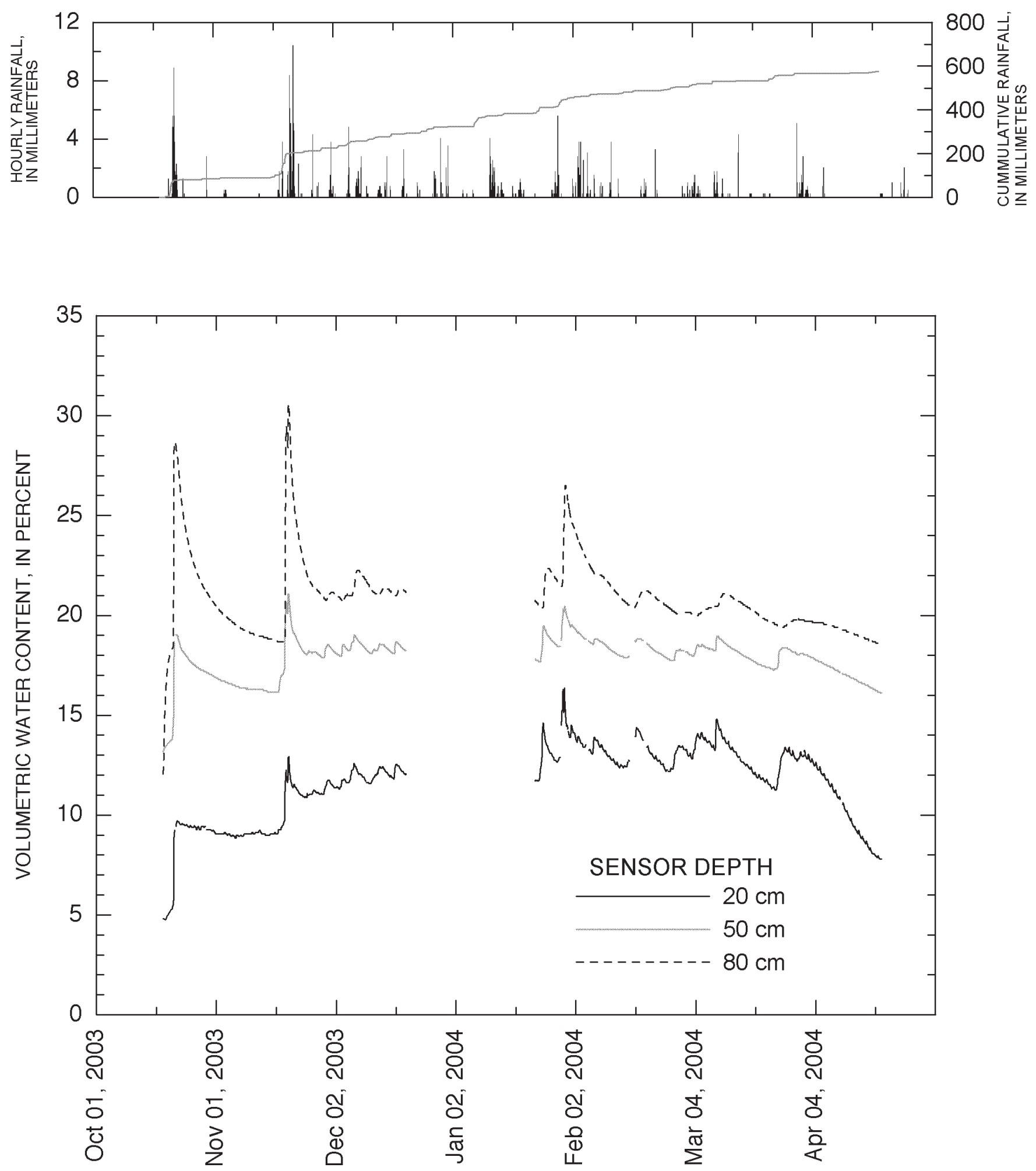

Figure 8. Hourly precipitation and soil wetness measured by water-content profilers from mid-October 2003 to late April 2004 at the Edmonds, Washington, site. Water-content reflectometers were removed in mid-October and replaced with two water-content profilers; figure 1B shows locations of the upper and lower boreholes. A. Soil wetness at depths of 20, 50 , and $80 \mathrm{~cm}$ in lower borehole. B. Soil wetness at depths of 100, 120, and $150 \mathrm{~cm}$ in lower borehole. C. Soil wetness at depths of 180 and $200 \mathrm{~cm}$ in lower borehole. D. Soil wetness at depths of 20,50, and $80 \mathrm{~cm}$ in upper borehole. E. Soil wetness at depths of 100, 120, and $150 \mathrm{~cm}$ in upper borehole. F. Soil wetness at depths of 180 and $200 \mathrm{~cm}$ in upper borehole. 
8B
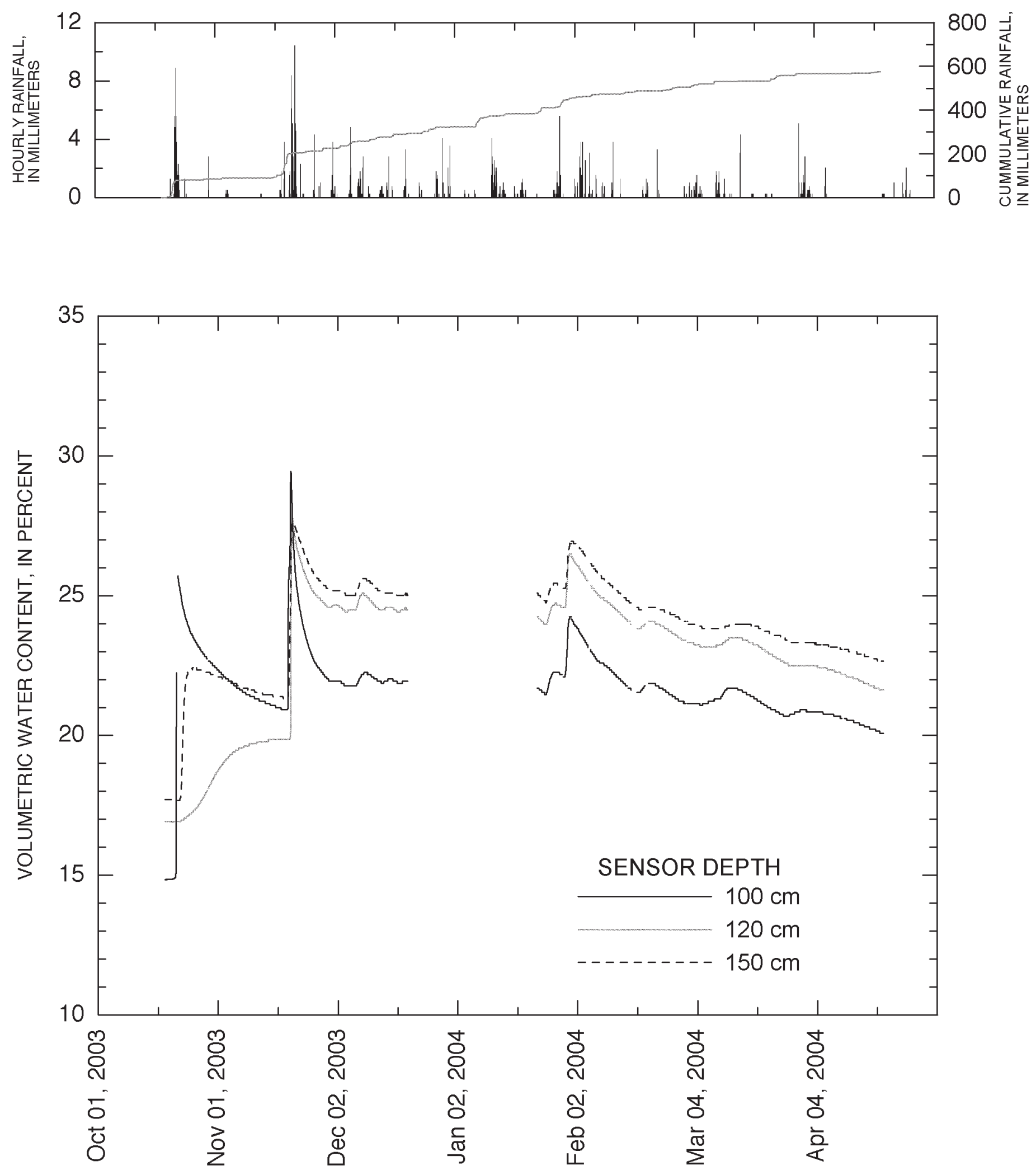
$8 \mathrm{C}$
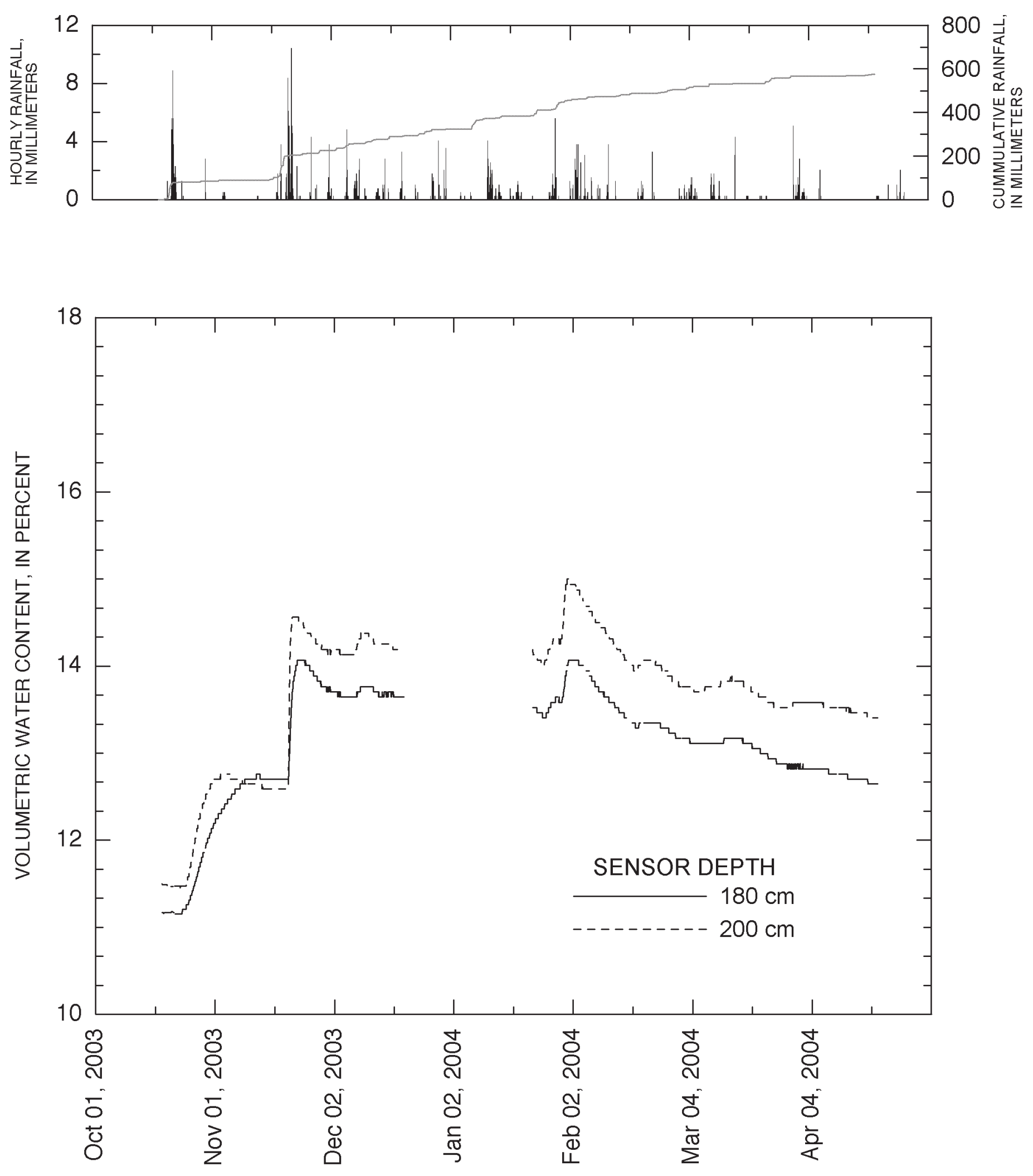
8D
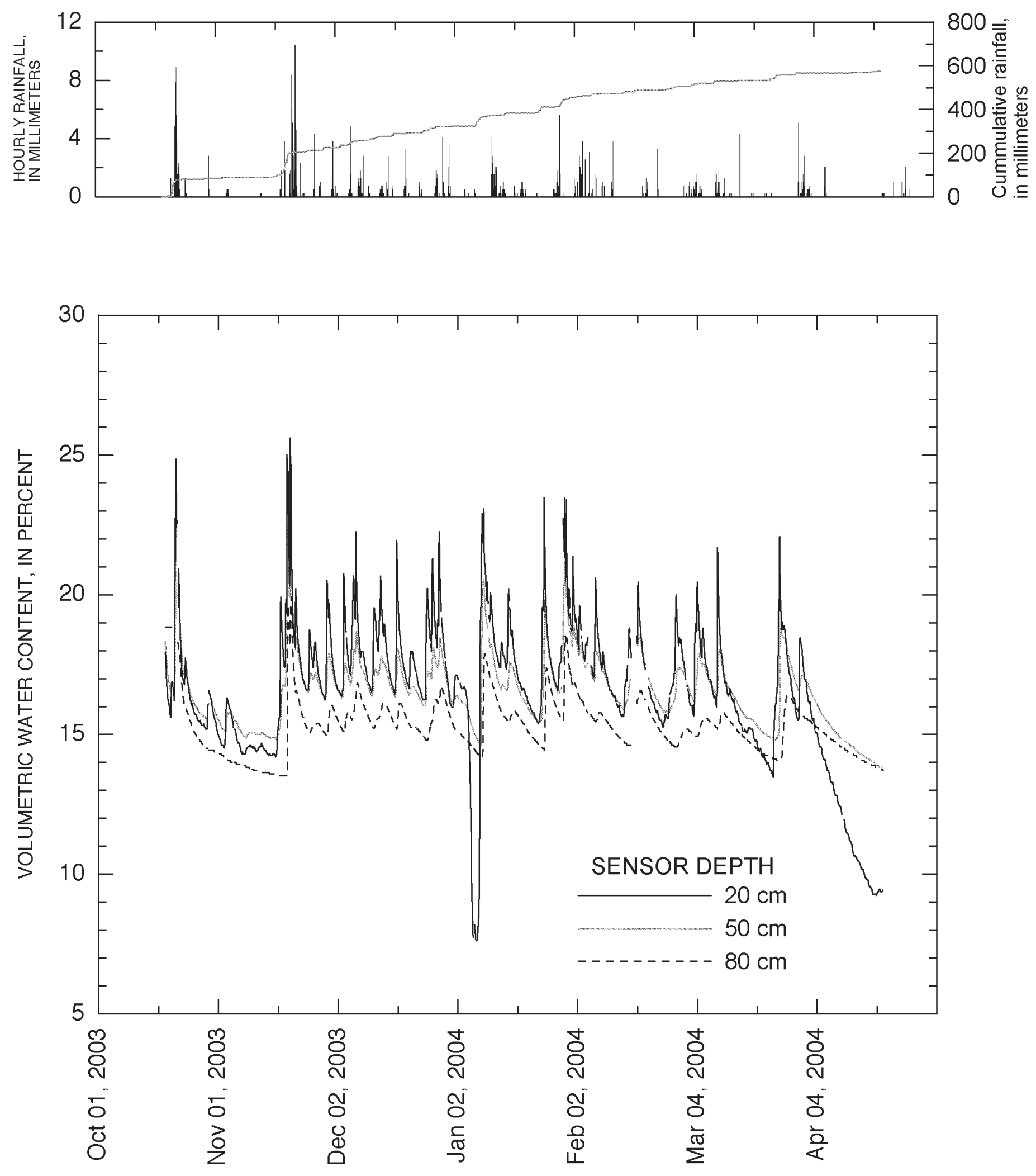
$8 \mathrm{E}$
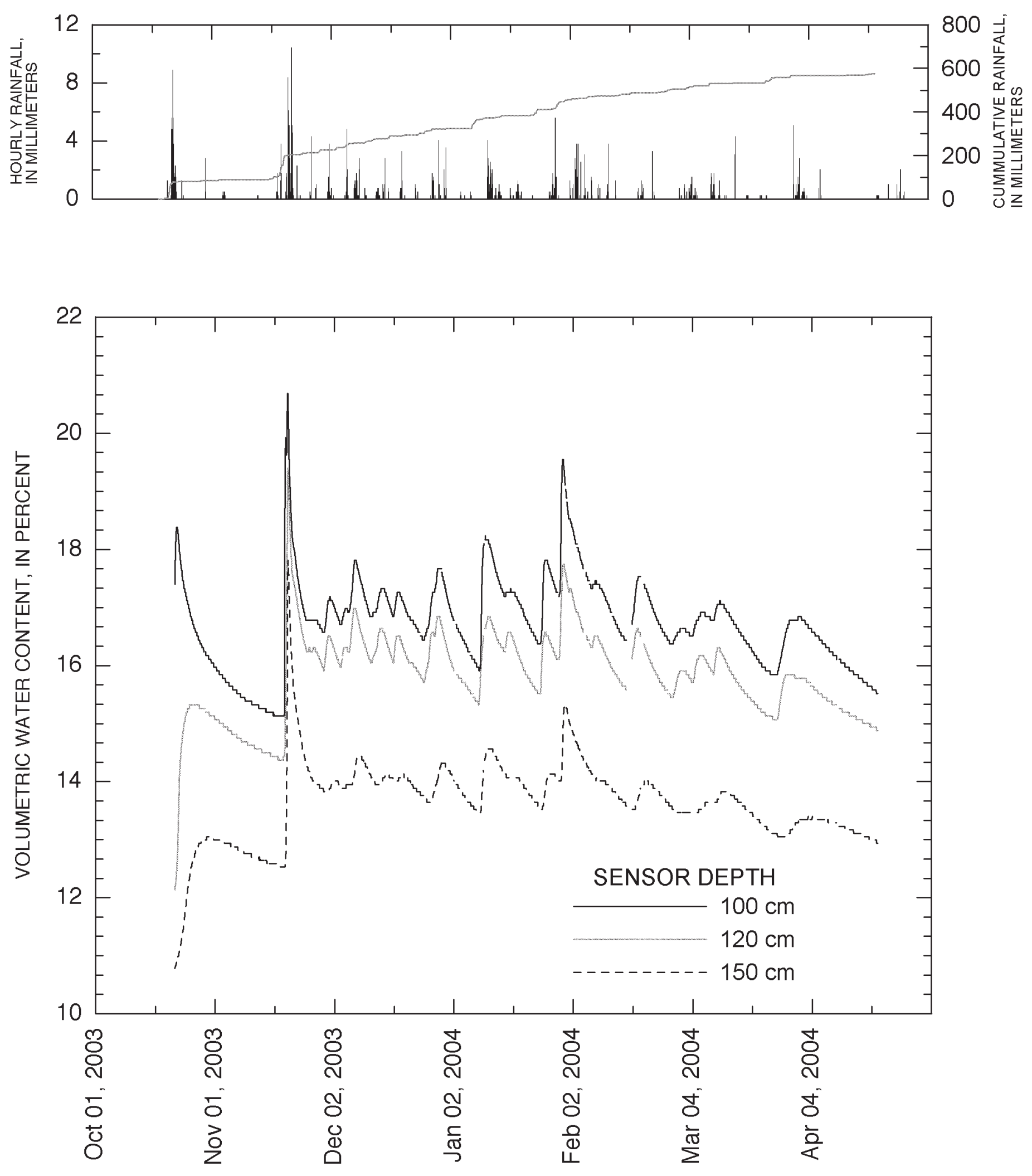
$8 \mathrm{~F}$
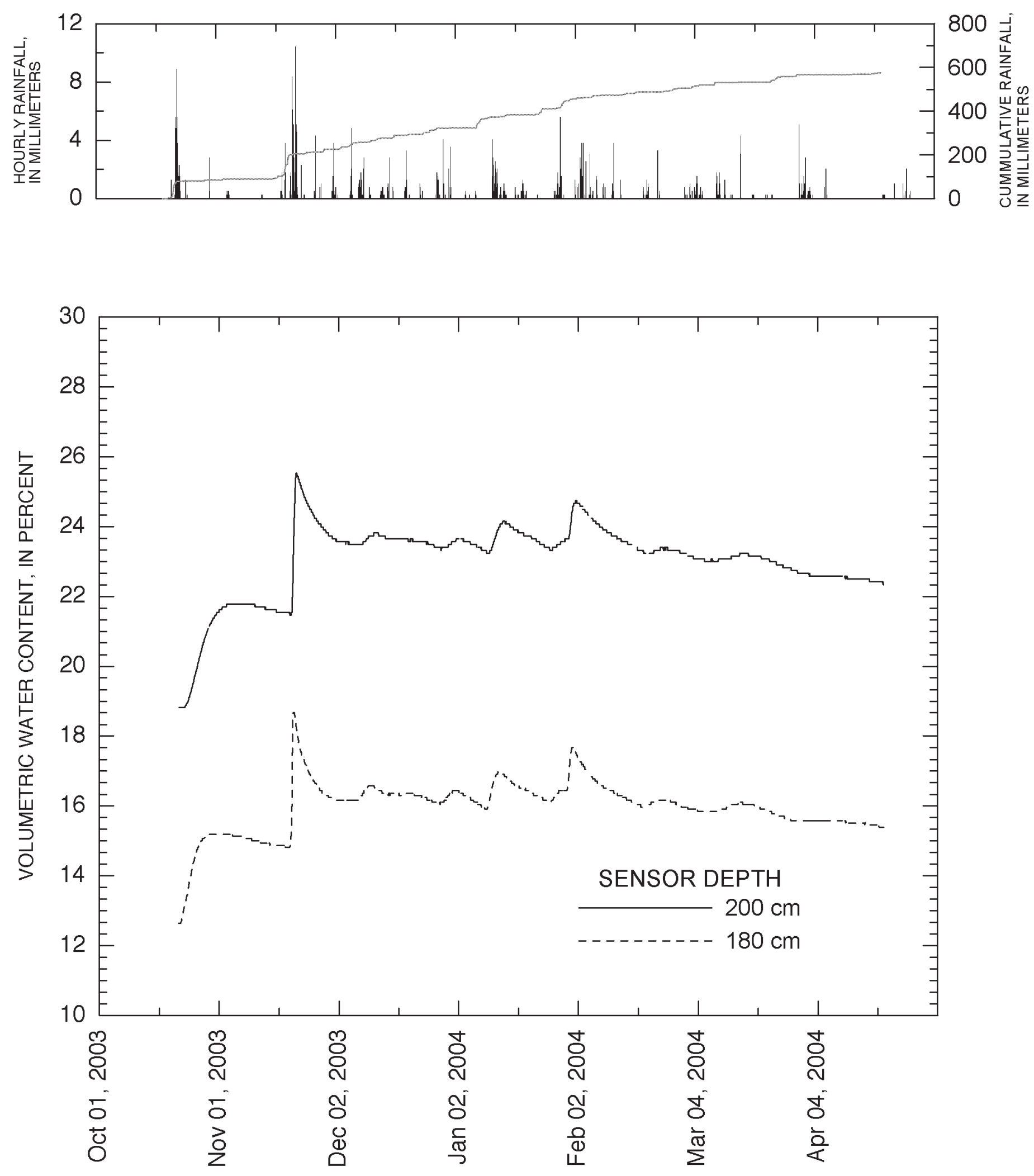
9A
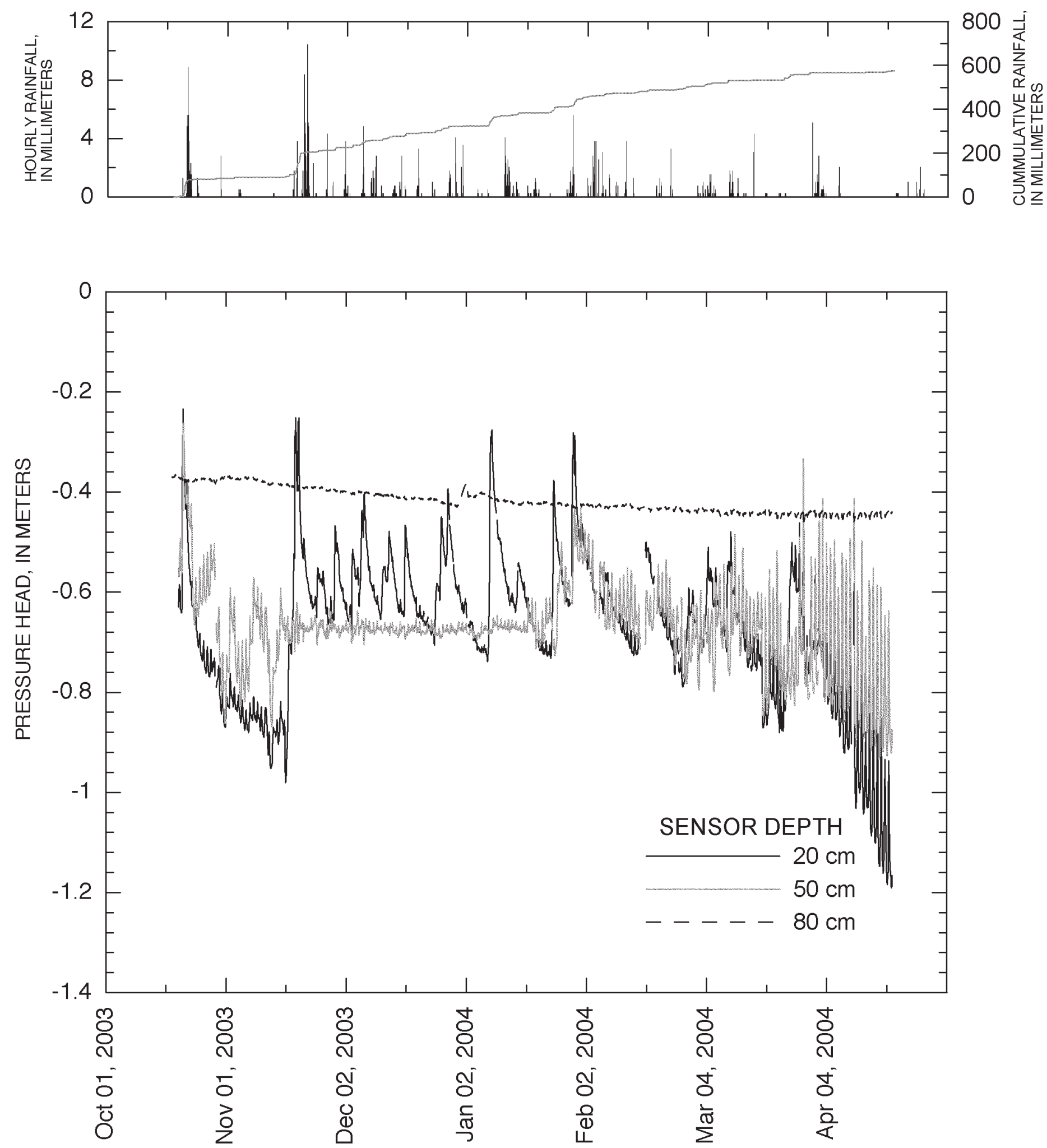

Figure 9. Hourly precipitation and pressure head measured by tensiometers from mid-October 2003 to late April 2004 at the Edmonds, Washington, site. Pressure transducers were removed in mid-October and replaced with two groups of tensiometers; figure 1B shows locations of the upper and lower tensiometer groups. A. Suction/pressure at depths of 20, 50, and $80 \mathrm{~cm}$ in lower tensiometer group. B. Suction/pressure at depths of 100,120 , and $150 \mathrm{~cm}$ in lower tensiometer group. C. Suction/pressure at depths of 20, 50 , and $80 \mathrm{~cm}$ in upper tensiometer group. D. Suction/pressure at depths of 100 and $120 \mathrm{~cm}$ in upper tensiometer group. 
9B
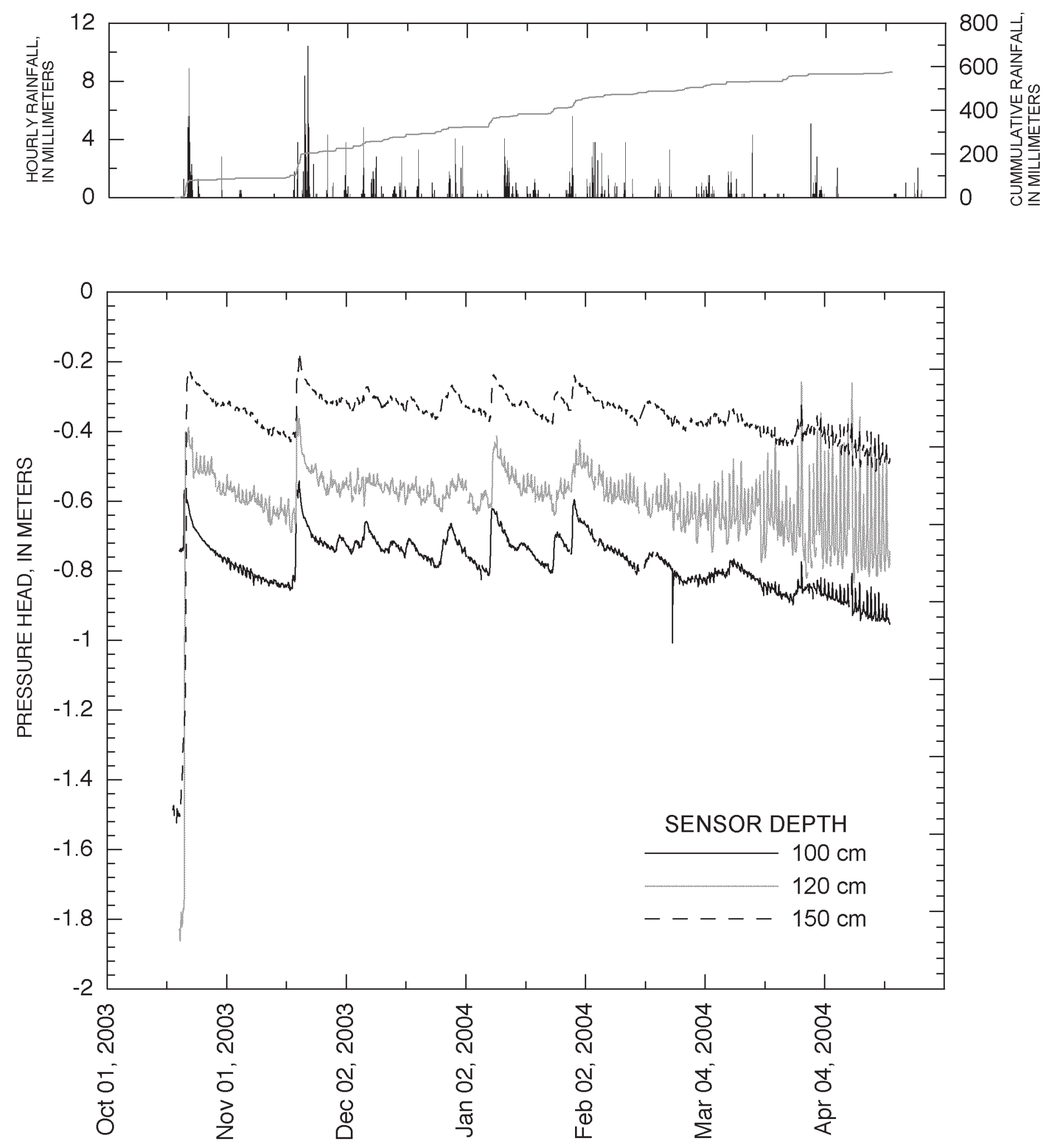
9C
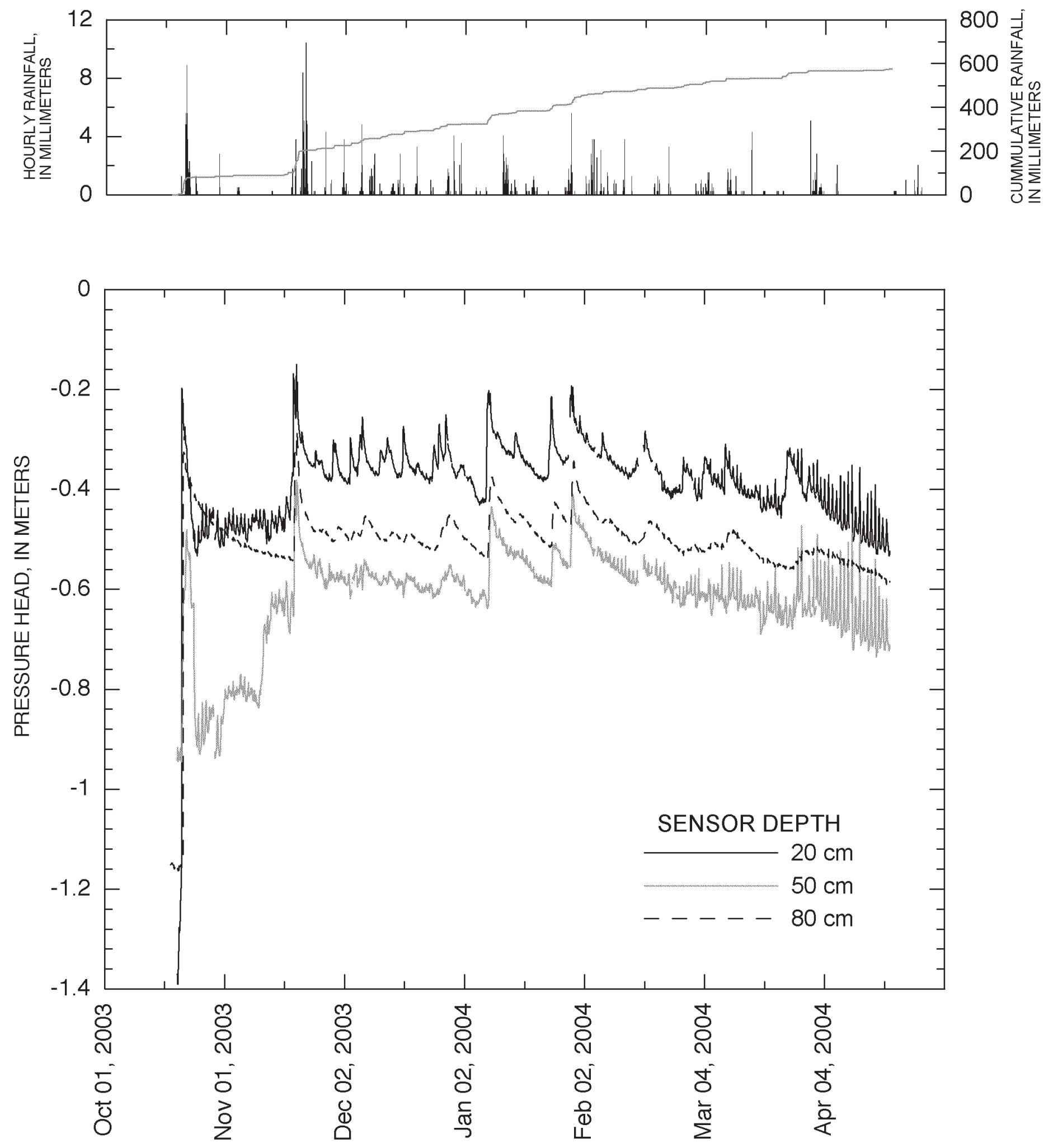
9D
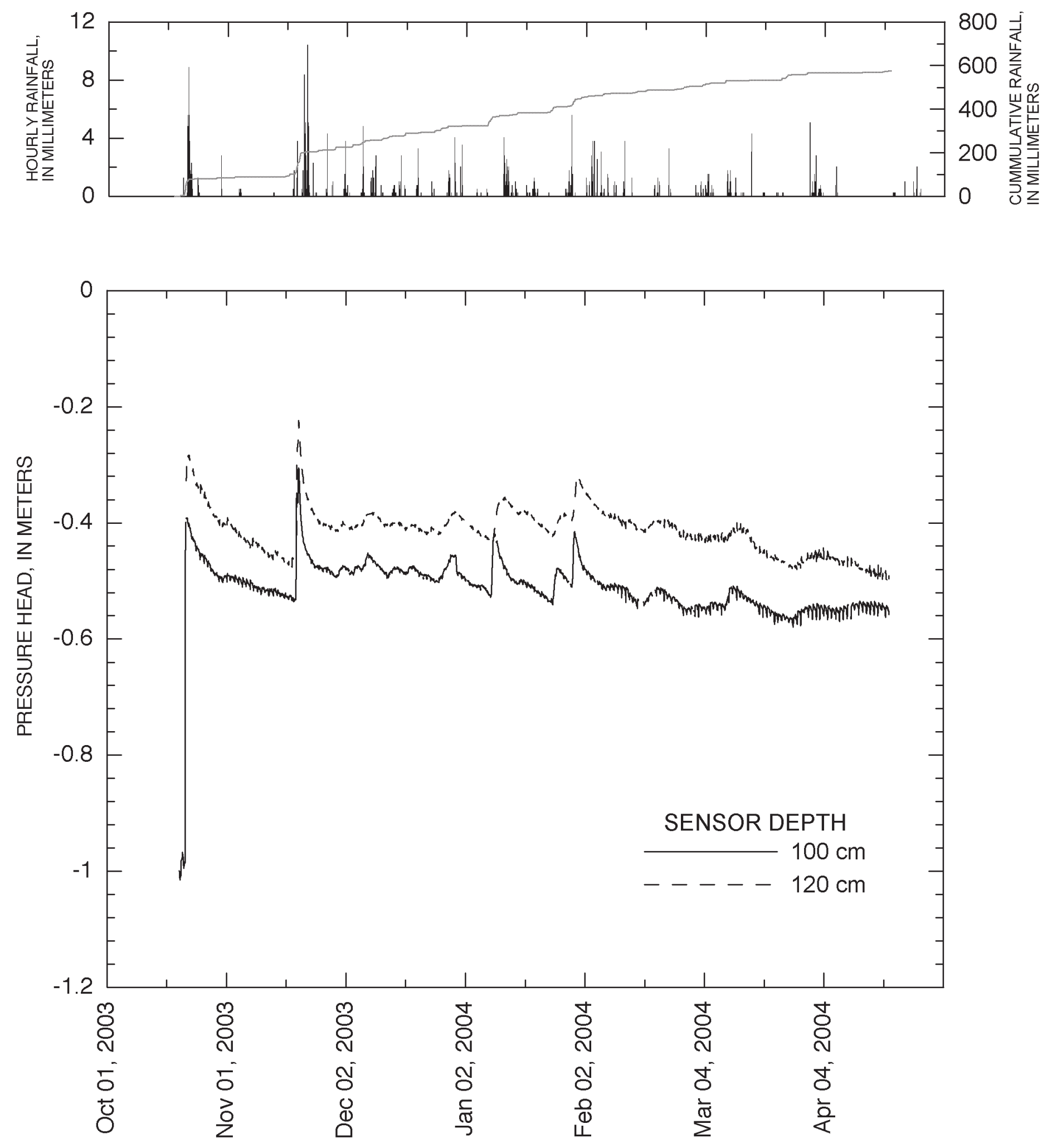


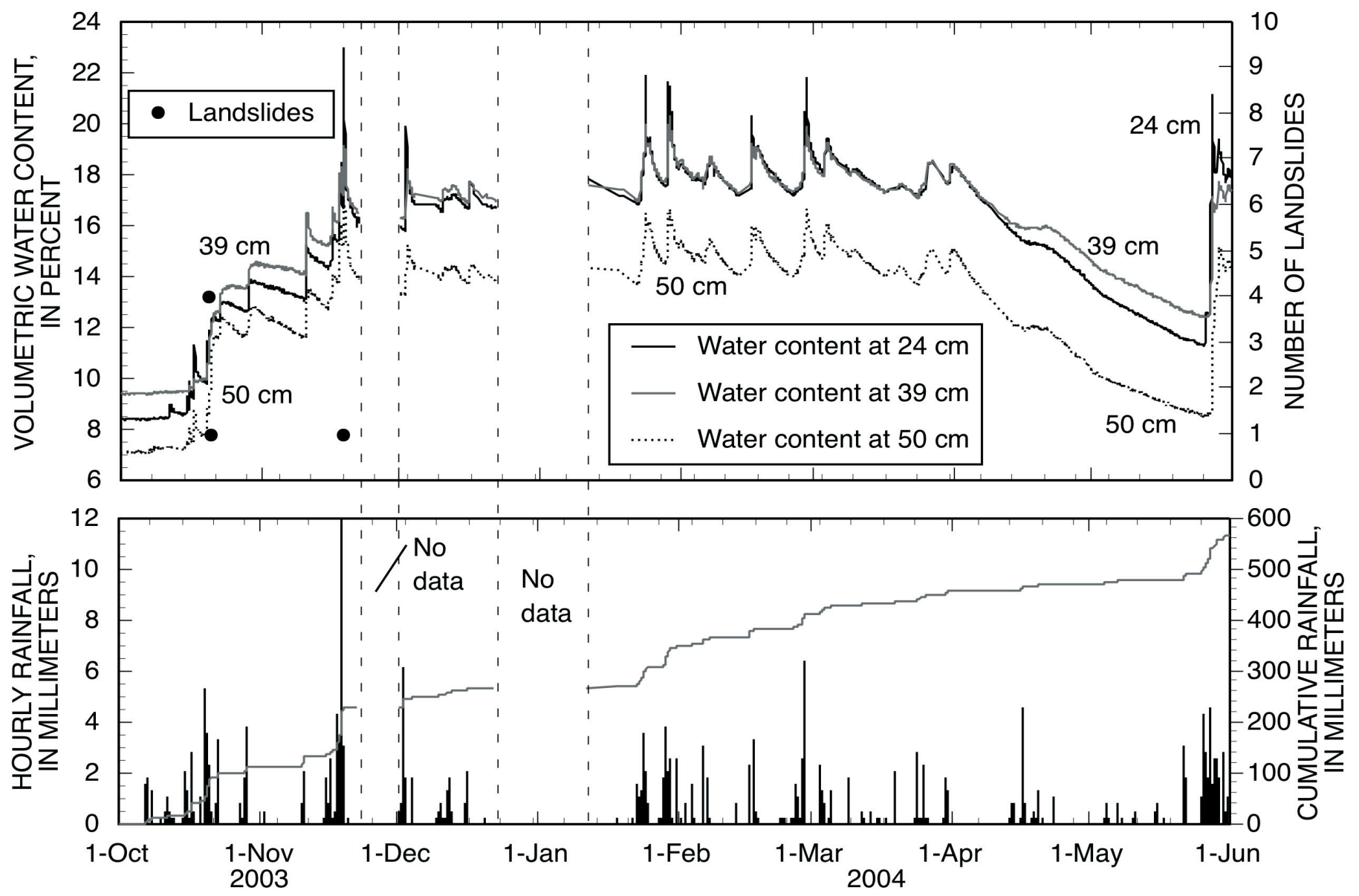

Figure 10. Hourly precipitation and soil wetness measured by water-content reflectometers at 24, 39, and $50 \mathrm{~cm}$ depth at the Everett, Washington, site. A. Observations from October 20, 2003, to May 31, 2004, dates and numbers of landslides in Seattle (Chleborad, 2003; Chleborad, A.F., U.S. Geological Survey, written commun., 2004). Major ticks on horizontal axis indicate months, and minor ticks indicate weeks. B. Detailed observations from October 1, 2003, to November 3, 2003. 


\section{B}
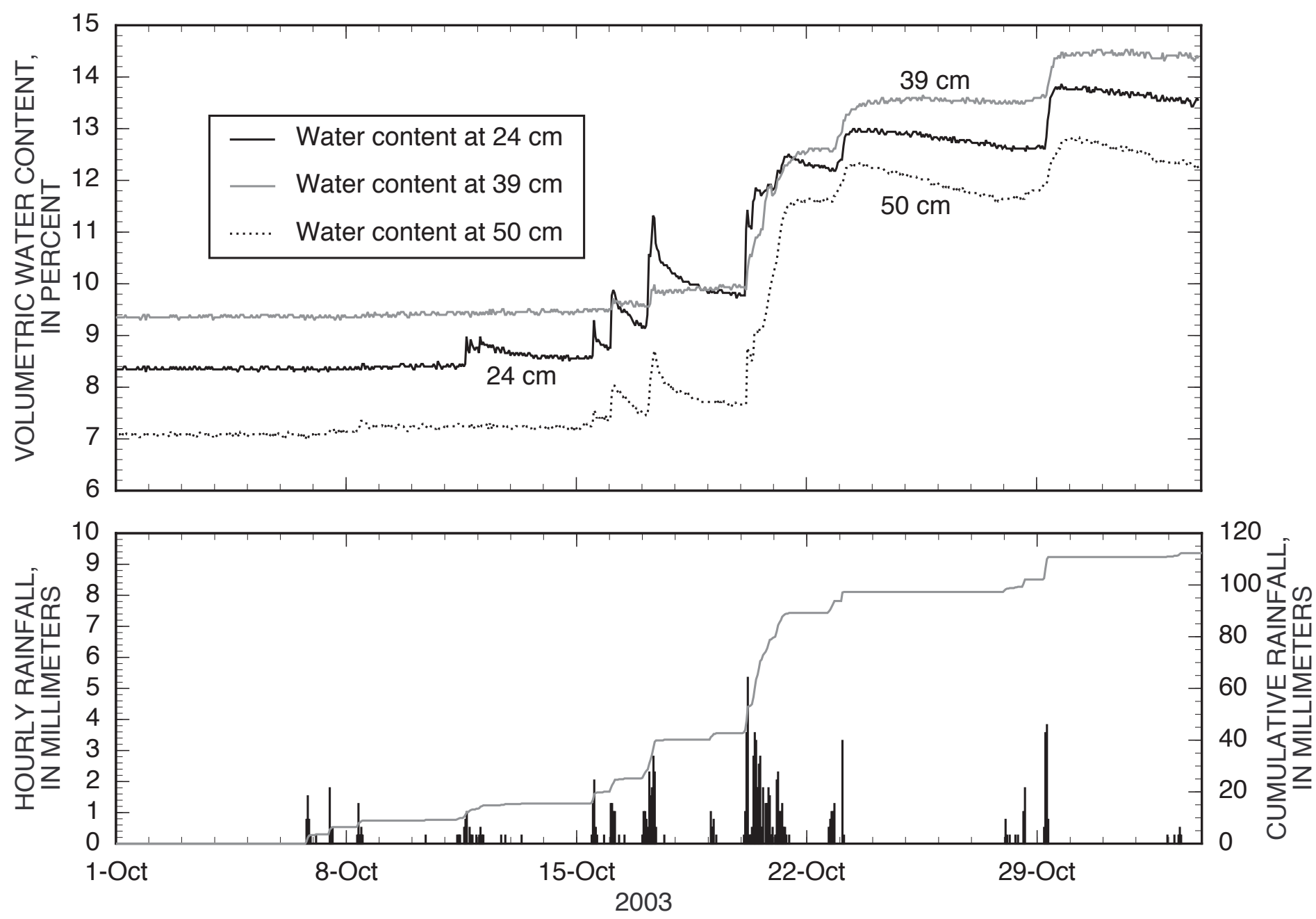
Table 2. Landslides on Puget Sound Coastal bluffs between Seattle and Everett, Washington.

[Except as noted, BNSF personnel reported the landslides included in this table to Shannon and Wilson, Inc. Numbers of landslides plotted in figures $3 \mathrm{~A}$ and $4 \mathrm{~A}$ exclude landslides listed here, leaders (--) indicate time of occurrence not known]

\begin{tabular}{|l|l|l|l|l|}
\hline \multicolumn{1}{|c|}{ Date } & \multicolumn{1}{|c|}{ Time } & \multicolumn{1}{c|}{$\begin{array}{c}\text { BNSF } \\
\text { milepost }\end{array}$} & \multicolumn{1}{|c|}{ Location } & \multicolumn{1}{c|}{ Comment } \\
\hline Nov. 29, 2001 & $3: 00$ a.m. & 29.2 & Mukilteo, Wash. & Jimmy Pang, BNSF \\
\hline Nov. 29, 2001 & $3: 00$ a.m. & 30.1 & Mukilteo, Wash. & Jimmy Pang, BNSF \\
\hline Nov. 30.2001 & Afternoon & 9.75 & Seattle. Wash. & Slump \\
\hline $\begin{array}{l}\text { Nov. 29-Dec. } \\
5.2001\end{array}$ & -- & 1784.3 & Near Everett monitoring site & Shallow slide depicted in figure 2 \\
\hline $\begin{array}{l}\text { Week of Nov. } \\
\text { 26.2001 }\end{array}$ & -- & 29.2 & Mukilteo, Wash. & Closed tracks \\
\hline $\begin{array}{l}\text { Late Nov. } \\
\text { 2001 }\end{array}$ & -- & 11.1 & Carkeek Park, Seattle, Wash. & Three small debris avalanches \\
\hline $\begin{array}{l}\text { Late Nov. } \\
2001\end{array}$ & -- & 11.3 & Carkeek Park, Seattle, Wash. & Two small debris avalanches \\
\hline $\begin{array}{l}\text { Late Nov. } \\
\text { 2001 }\end{array}$ & -- & $10.4-10.5$ & Carkeek Park, Seattle, Wash. & A few small slides \\
\hline
\end{tabular}

the distance between them, weather in Seattle, Edmonds, and Everett is similar enough that useful, although approximate, correlations between the timing of landslides and the timing of precipitation, increases in soil wetness, and pressure head can be made in absence of sufficient landslide data close to the monitoring sites. Most of the landslides occurred in Seattle during a wet period that lasted from mid-November 2001 through January 2002 (fig. 3A and 4A). One landslide occurred about $200 \mathrm{~m}$ from the Everett site between November 29, 2001, and December 05, 2001, shortly after monitoring began (fig. 2, 4A). Several other landslides were reported along coastal bluffs between Seattle and Everett during the last few days of November 2001 (table 2). Limited data are available from that time period as we were continuing to solve problems with the instrumentation. However, soil wetness at a depth of $74 \mathrm{~cm}$ at Everett was relatively steady from the time of our earliest data on October 12, 2001 until October 27, 2001, when it rose abruptly (fig. 4A). Although soil wetness fluctuated a few percent in response to storms, it remained elevated until at least mid-May 2002. Thus, soil wetness at Everett had risen to wetseason conditions prior to occurrence of prolonged precipitation associated with landslides that occurred in Seattle (Chleborad, 2003) and near Everett. Soil wetness at Edmonds $(69 \mathrm{~cm}$ depth) remained relatively low until late November after several landslides had occurred in Seattle, but the rise coincided with the timing of landslides reported on the coastal bluffs (table 2, fig. $4 \mathrm{~A})$.
Several landslides also occurred in and around Seattle on December 16-20, 2001 (fig. 3A and 4A; Chleborad, 2003). These correspond to the largest recorded rise in soil wetness at Edmonds during the 2001-2002 monitoring season (fig. 3A and 3C); the December 16-17 storm produced less rain at Everett and a smaller rise in soil wetness (fig. 4 A and 4B). Only two landslides were reported in Seattle during 2002-2003, both coinciding with rainfall. The one on November 23, 2002, does not coincide with high antecedent soil wetness but one on March 22, 2003, clearly coincides with elevated soil wetness. Landslides reported in Seattle during the 2003-2004 season coincide with major rainfall on October 20, 2003, and November 19, 2003 (fig. 10A) - four landslides on October 20, one on October 21, and one on November 19, 2003. Soil wetness was low in October and relatively high in November 2003.

Overall, most landslides during the period of monitoring occurred when antecedent soil wetness was high; furthermore, clusters of three or more landslides on one day typically occurred during or directly after significant rainfall (more than $30 \mathrm{~mm}$ of rain in 24 hours preceding the landslides). Using larger data sets for Seattle, Chleborad (2000, 2003) and Godt (2004) have defined more precise relations between rainfall and landslide occurrence. Soil wetness at a given depth might be best characterized relative to soil wetness near the end of the dry season (August and September). Antecedent soil wetness at the time of most landslides was at least 4 percent higher, and in many cases, more 
than 8 or 10 percent higher than the dry season wetness at the same depth (figs. 3, 4, 5, 7, 8, and 10). The rainfall that triggered clusters of landslides typically raised soil wetness an additional 2 to 4 percent within several hours. The observed increases in soil wetness correspond to two- or three-fold greater increases in the degree of saturation of the soil because the wetness (volumetric water content) is based on the bulk volume of the soil, but the degree of saturation is based on the volume of the pore space, and the porosity of uniform sand like that found at the monitoring sites is generally between 30 and 50 percent of the bulk volume (Lambe and Whitman, 1969).

\section{Discussion and Conclusions}

Despite difficulties that have resulted in incomplete data for the past three rainy seasons, our data help to clarify the roles of antecedent soil wetness and relatively intense precipitation in triggering shallow landslides on the coastal bluffs between Seattle and Everett. Our data and observations indicate that landslide activity usually requires a combination of wet antecedent conditions followed by one or more days of relatively intense rainfall, consistent with the findings of Chleborad's (2003) analysis of a precipitation threshold for landslide occurrence. Even the record-breaking rainfall of October 2003 produced few landslides because of dry antecedent conditions. Wet antecedent conditions generally are achieved sometime between mid-October and late December, and remain until March or April, but the exact time varies from year to year and place to place, depending on the timing and amounts of precipitation. Preliminary analysis of our data indicates that continuous monitoring of soil wetness is the most reliable way to determine when the upper 1-2 $\mathrm{m}$ of soil has been wetted sufficiently to be susceptible to landslides. Continuous monitoring of precipitation (preferably supplemented by tensiometric observations) is needed to forecast landslide activity once wet antecedent conditions have been achieved. Additional monitoring using tensiometers is needed to determine details (at finer time scales) of pore-water response to rainfall. Forecasts could be made either by means of empirical rainfall thresholds (Chleborad, 2000; 2003) or by means of simple physical models (Savage and others, 2003), both of which are currently under development at the USGS.

Our observations have important implications for modeling infiltration, subsurface water flow, and slope instability of the bluffs. Instrumental observations indicate that the upper two meters of soil rarely becomes saturated and that the flow of soil water there has a strong downward component during and directly after storms. Consequently, time-dependent, vertical infiltration models for unsaturated soils should be able to explain most of the features of our soil-wetness and porepressure data (Srivastava and Yeh, 1991; Simunek and others, 1998). Unsaturated soil mechanics principles and data may be required to understand occurrence of shallow landslides on the bluffs. Visual observations indicate that saturated zones and lateral flow of ground water do exist locally in the bluffs (fig. 2); consequently, two- or three-dimensional models probably would be needed to represent conditions at sites larger than the vertical profiles represented by our field measurements.

Based on our preliminary analysis of monitoring data and instrument performance, an ideal monitoring system for early warning of landslide activity on coastal bluffs of Puget Sound would consist of stations for continuously monitoring precipitation and soil wetness between the surface and $2 \mathrm{~m}$ depth. Tensiometers would provide a valuable addition at sites that can be accessed easily for maintenance. However, piezometers do not appear to be useful in this setting, unless a perennial saturated zone is present at the site. Improvements such as permanent AC power sources, direct-burial cable or spread-spectrum communications between the datalogger and hillside sensors, and redundant sensors and dataloggers would be needed to develop existing monitoring systems into permanent, reliable installations for long-term scientific monitoring or use in early warning of landslide activity. A regular maintenance program for the field sites would help ensure reliable operations.

\section{Literature Cited}

Baum, R.L., Chleborad, A.F., and Schuster, R.L., 1998, Landslides triggered by the December 1996 and January 1997 storms in the Puget Sound area, Washington: U.S. Geological Survey Open-File Report 98-239, 16 p., on-line at http://pubs.usgs.gov/of/1998/ofr-98-239/

Baum, R.L., Harp, E.L., and Hultman, W.A., 2000, Map showing recent and historic landslide activity on coastal bluffs of Puget Sound between Shilshole Bay and Everett, Washington, U.S. Geological Survey Miscellaneous Field Studies Map, MF 2346, 1 sheet, 1:24,000, on-line at http://pubs.usgs.gov/mf/2000/mf-2346/

Baum, R.L., Harp, E.L., McKenna, J.P., McMullen, S.R., Kibler, J.D., and Barnett, Elizabeth, 2002a, Application of nearreal-time monitoring to study of coastal bluff instability, Snohomish County, Washington: Geological Society of America Cordilleran Section Meeting, May 13-15, Abstracts with Programs, v. 34, no. 5, p. A-23.

Baum, R.L., Harp, E.L., McMullen, S.R., McKenna, J.P., and Kibler, J.D., 2002b, Near-real-time monitoring pilot project for reducing landslide hazard in the Seattle-Everett, Washington, rail corridor: Geological Society of America Annual Meeting, October 27-30, Abstracts with Programs, v. 34 , no. 6 , p. 91 .

Bouwer, Herman, 1989, The Bouwer and Rice slug test-An update: Groundwater, v. 27, p. 304-309.

Bouwer, Herman, and Rice, R.C., 1976, A slug test for determining hydraulic conductivity of unconfined aquifers in completely or partially penetrating wells: Water Resources Research, v. 12, p. 423-428. 
Campbell Scientific, Inc., 1996, CS615 Water Content Reflectometer Instruction Manual, version 8221-07: Logan, Utah, Campbell Scientific, Inc., 12 p.

Chleborad, A.F., 2000, A method for anticipating the occurrence of precipitation-induced landslides in Seattle, Washington: U.S. Geological Survey Open-File Report 00-469, 29 p.

Chleborad A.F., 2003, Preliminary evaluation of a precipitation threshold for anticipating the occurrence of landslides in the Seattle, Washington, Area: U.S. Geological Survey OpenFile Report 03-463, 39 p.

Freeze, R.A., and Cherry, J.A., 1979, Groundwater: Englewood Cliffs, New Jersey, Prentice-Hall, 604 p.

Godt, J.W., 2004, Observed and modeled conditions for shallow landsliding in the Seattle, Washington, area: Boulder, University of Colorado, Ph.D. dissertation, 151 p., 1 pl., 32 figs.

Hillel, Daniel, 1982, Introduction to Soil Physics: San Diego, Academic Press, 364 p.

Lambe, T.W., and Whitman, R.V., 1969, Soil Mechanics: New York, Wiley, 553 p.

McKenna, J.P., Godt, J.W., and Baum, R.L., 2004, Instrumental observations of unsaturated zone hydrology and slope stability-Puget Sound coastal bluffs: Geological Society of America Abstracts with Programs, v. 36, no. 4, p. 15

Minard, James P., 1983, Geologic Map of the Edmonds East and part of the Edmonds West Quadrangles, Washington: U.S. Geological Survey Miscellaneous Field Studies Map MF-1541.
Minard, James P., 1985, Geologic Map of the Everett 7.5Minute Quadrangle, Snohomish County, Washington: U.S. Geological Survey Miscellaneous Field Studies Map MF-1748.

Savage, W.Z., Morrissey, M.M., and Baum, R.L., 2000, Geotechnical properties for landslide prone Seattle area glacial deposits: U.S. Geological Survey Open-File Report 00-228, 5 p.

Savage, W.Z., Godt, J.W., and Baum, R.L., 2003, A model for spatially and temporally distributed shallow landslide initiation by rainfall infiltration, in Rickenmann, Dieter, and Chen, Cheng-lung, eds., Debris-flow hazards mitigationMechanics, prediction, and assessment, Rotterdam, Millpress (Proceedings of the 3rd International conference on Debris Flow Hazards Mitigation, Davos, Switzerland, September 10-13, 2003), p. 179-187.

Simunek, Jirka, Huang, K., and van Genuchten, M.Th., 1998, The HYDRUS code for simulating 1-dimensional movement of water, heat, and multiple solutes in variably saturated media, version 6.0: Riverside, Calif., U.S. Salinity Laboratory Research Report No. 144.

Srivastava, Rajesh, and Yeh, T.-C. J., 1991, Analytical solutions for one-dimensional, transient infiltration toward the water table in homogeneous and layered soils: Water Resources Research v. 27, p. 753-762. 